\title{
El Parlamento de Andalucía a través de sus reglamentos $^{1}$
}

\author{
Javier Pardo Falcón \\ Letrado del Parlamento de Andalucía \\ Profesor Titular de Derecho Constitucional
}

\begin{abstract}
SUMARIO: Introducción.- PRIMERA PARTE: LA FORMACIÓN DEL SISTEMA PARLAMENTARIO ANDALUZ.- I. Los primeros reglamentos: del mimetismo estatal al reconocimiento de las peculiaridades autonómicas.- II. La denominada legislatura "de la pinza" (19941996): el Reglamento como garante de nuevos derechos de los agentes políticos y sociales en el ámbito parlamentario-. III. El Reglamento de 2005: la afirmación de un modelo parlamentario andaluz y sus nuevas tendencias.- SEGUNDA PARTE: LA CONSOLIDACIÓN DEL SISTEMA PARLAMENTARIO ANDALUZ. El REGLAMENTO DEL PARLAMENTO ANDALUCÍA A LA LUZ DEL NUEVO ESTATUTO DE AUTONOMÍA.- I. El mantenimiento de los rasgos esenciales del régimen parlamentario andaluz en el Estatuto de Autonomía de 2007.- II. Las nuevas previsiones estatutarias con incidencia directa en el Reglamento: su progresiva incorporación al ordenamiento parlamentario mediante normas infrarreglamentarias.- III. Una medida pionera en el sistema parlamentario español: la delegación del voto.- IV. Primera reacción ante los síntomas de crisis de la democracia representativa: el fortalecimiento de la iniciativa legislativa popular.- V. La última reforma (o más bien "revisión") del Reglamento: la traslación al ámbito parlamentario de los principios de "transparencia" y "calidad democrática”.- VI. Para concluir: algunas reformas necesarias y otras siempre pendientes.
\end{abstract}

\footnotetext{
${ }^{1}$ Este trabajo es una reelaboración actualizada de la exposición que sobre las reformas -en particular las entonces más recientes- habidas en el Reglamento del Parlamento de Andalucía realicé en el marco de los Cursos de Verano de la Universidad de Cantabria, concretamente el curso celebrado en julio de 2009 en la localidad de Reocín sobre el tema "Nuevas tendencias en el Derecho Parlamentario". Quiero reiterar, como ya hice entonces, mi agradecimiento a los compañeros Ángel Luis Sanz Pérez y Luis González del Campo, letrados de la Asamblea de Cantabria, por invitarme a participar en dicho curso junto con otros estimados compañeros y prestigiosos expertos en la materia.
} 
RESUMEN: El 16 de abril de 2015 dio comienzo la X Legislatura del Parlamento de Andalucía. Transcurridas ya más de tres décadas desde su puesta en marcha, muchos han sido los cambios operados en dicho órgano, tanto en lo que se refiere a su organización como a su funcionamiento. Partiendo de la indiscutible relevancia que a estos efectos poseen los reglamentos de las cámaras así como otras destacadas normas de origen parlamentario, el presente trabajo se plantea como un estudio "introspectivo" del Parlamento de Andalucía a través de las sucesivas reformas de las que directa o indirectamente ha sido objeto su Reglamento. Y ello con la finalidad de apreciar, mediante la exposición y análisis de tales reformas, la evolución de la cámara en el plano normativo interno desde su constitución inicial hasta el momento actual.

PALABRAS CLAVES: Parlamento de Andalucía, Cámaras legislativas, Reglamento parlamentario.

ABSTRACT: The April 16, 2015 the $X$ Legislature of the Andalusian Parliament began. More than three decades since its start up, there have been many changes in the institution, both as regards their organization and operation. Starting from the indisputable importance of the parliamentary rules and other relevant regulations of the parliamentary origin, this paper is conceived as an "introspective" study of the Andalusian Parliament through successive reforms that directly or indirectly its regulation has undergone. All in order to appreciate through the presentation and analysis of those, the evolution of the camera in the prescriptive level from its origins until the present day.

KEYWORDS: Andalusian Parliament, Legislative chambers, Parliamentary rules.

\section{Introducción}

El 16 de abril de 2015, con la celebración de la sesión constitutiva, dio comienzo la X Legislatura del Parlamento de Andalucía. Transcurridas ya más de tres décadas desde el inicio de su I Legislatura ${ }^{2}$, muchos han sido también como es lógico los cambios operados en dicho órgano desde entonces, tanto en lo que se refiere a su composición como a su actividad. Baste recodar a estos efectos que de los cinco grupos parlamentarios constituidos en esa legislatura inicial se pasó a los tres que han teni-

${ }^{2}$ La primera sesión constitutiva del Parlamento de Andalucía tuvo lugar el 21 de junio de 1982, en el Salón de Tapices de los Reales Alcázares de Sevilla. 
do presencia en la Cámara durante la VIII y IX ${ }^{3}$. De otra parte, el número de iniciativas legislativas aprobadas también se ha incrementado progresivamente, sin que haya sido ni mucho menos ajeno a dicha circunstancia el reconocimiento al Consejo Gobierno en el nuevo Estatuto de Autonomía para Andalucía de la facultad de dictar decretos-leyes ${ }^{4}$.

Pero no es el objeto de estas páginas realizar un análisis politológico del comportamiento de los agentes parlamentarios a lo largo de esas nueve legislaturas anteriores. Tampoco efectuar balance de ningún tipo sobre la actividad normativa desplegada por la Cámara en los distintos ámbitos competenciales reconocidos a la Comunidad Autónoma por los dos estatutos de autonomía sucesivamente en vigor ni sus efectos sobre el conjunto de la ciudadanía andaluza. Muy al contrario, partiendo de la preponderancia de los reglamentos de las cámaras respecto del resto de las normas de origen parlamentario (presupuestarias, administrativas, disciplinarias), puesta de manifiesto en la propia estructura del art. 102 del Estatuto ${ }^{5}$, el presente trabajo se plantea, estrictamente, como un estudio "introspectivo" de Parlamento de Andalucía. Y ello con la finalidad de apreciar, a través de la sucesivas reformas parciales o generales que ha sufrido la versión inicial de su Reglamento ${ }^{6}$, la evolución de la Cámara en el plano normativo interno y los cambios que, en consecuencia, ha ido experimentando la institución en todo lo concerniente a su organización y funcionamiento desde su constitución inicial hasta el momento actual. En concreto, estás reformas han sido doce ${ }^{7}$, si bien habría que distinguir entre ellas, y así se hará aquí, las

${ }^{3}$ En efecto, en la I Legislatura se constituyeron cinco grupos parlamentarios correspondientes a otras tantas formaciones políticas [PSOE, AP-PDP-UL, UCD, IU-CA y PSA]; desde la II y hasta la VII, ambas inclusive, cuatro [PSOE, AP-PDP-PL (después PP), IU-CA (después IULV-CA) y PA (Coalición Andalucista en la IV Legislatura)] y, en la VIII y IX, tres (PSOE, PP e IULV-CA).

${ }^{4} 45$ iniciativas de carácter legislativo en la I Legislatura; 30 en la II; 24 en la III; 9 en la IV; 45 en la V; 46 en la VI; 59 en la VII; 60 en la VIII y 51 en la IX.

${ }^{5}$ Así lo demuestran las reiteradas alusiones más o menos explícitas al Reglamento del Parlamento de Andalucía (RPA) en los cuatro apartados del citado artículo, cuya rúbrica es Autonomía Parlamentaria. Véase en este sentido el comentario de J.M. Morales Arroyo al art. 102 del Estatuto de Autonomía para Andalucía (EAA) en P. Cruz Villalón-M. Medina Guerrero (dirs.): Comentario al Estatuto de Autonomía para Andalucía, (vol. III), Parlamento de Andalucía, Ideas Más Tecnología, Sevilla, 2012, pág. 1674.

${ }^{6}$ Publicada en del Boletín Oficial del Parlamento de Andalucía (BOPA) núm. 12, de 12 de noviembre de 1982.

${ }^{7}$ Las mismas aparecen publicadas en los siguientes números del BOPA: Núm. 60, de 30 de abril de 1991; núm. 76, de 5 de mayo de 1995; núm. 27, de 18 de julio de 1996; núm. 615, de 7 de enero de 2004; núm. 88, de 19 de mayo de 2004; núm. 292, de 4 de octubre de 2005; núm. 768, de 27 de noviembre de 2007; núm. 10, de 2 de mayo de 2008; núm. 323, de 22 de octubre de 2009; núm. 433, de 8 de abril de 2010; núm. 90, de 24 de octubre de 2012, y núm. 576, de 3 de diciembre de 2014. 
que han tenido un carácter técnico o puntual de las que deben considerarse verdaderas revisiones del texto reglamentario con un indudable alcance político. A unas y otras nos referimos a continuación.

\section{PRIMERA PARTE: LA FORMAGIÓN DEL SISTEMA PAR- LAMENTARIO ANDALUZ}

\section{LOS PRIMEROS REGLAMENTOS: DEL MIMETISMO ES- TATAL AL REGONOCIMIENTO DE LAS PECULIARIDA- DES AUTONOMICAS}

Al amparo de lo establecido en el art. 27.2 del primer Estatuto de Autonomía para Andalucía, aprobado en referéndum por los ciudadanos andaluces el 20 de octubre de 1981, el Parlamento de Andalucía aprueba también su primer Reglamento en noviembre de 1982, seis meses después de las primeras elecciones autonómicas ${ }^{8}$. Al igual que los otros tres parlamentos autonómicos que le habían precedido en su constitución (los de las denominadas comunidades históricas del País Vasco, Cataluña y Galicia), este primer texto reglamentario está fuertemente influenciado, como no dejaba de ser lógico, por el Reglamento del Congreso de los Diputados aprobado algunos meses antes, concretamente el 10 de febrero de 1982. Hasta tal punto ello era así que, como expresivamente se ha dicho, con este primer Reglamento parece que los parlamentarios andaluces "intentaron adaptar una institución, el Parlamento de Andalucía, a una norma"9. Y es que, en efecto, su fidelidad al Reglamento del Congreso era tal que las variaciones del texto andaluz responderán casi exclusivamente a las diferencias de nomenclatura existentes entre instituciones y órganos andaluces y estatales o tendrán su explicación en las competencias atribuidas por la Constitución a la citada cámara de las Cortes Generales sin equivalente en el caso de las asambleas autonómicas. De cualquier modo, si esta reproducción del Reglamento del Congreso por su homólogo andaluz podía tener algún sentido era justamente en esta I Legislatura (1982-1986), única, hasta la actual X Legislatura, en la que la Cámara legislativa autonómica va a estar integrada por cinco grupos parlamentarios represen-

${ }^{8}$ Diario de Sesiones del Parlamento de Andalucía (DSPA) núm. 6, de 3 de noviembre de 1982.

${ }^{9}$ De esta manera lo expresaban J. M. Morales Arroyo y M. J. Terol Becerra en su presentación del Reglamento del Parlamento de Andalucía (pág. 16), como responsables de la edición de dicho Reglamento dentro de la colección Textos Legislativos, del Servicio de Publicaciones del Parlamento de Andalucía (Sevilla, 1997). 
tativos de otras tantas fuerzas políticas, la mayoría de ellas de ámbito estatal ${ }^{10}$. Tal composición se mantendría con alguna variación en la II Legislatura (1986-1990) ${ }^{11}$.

A partir de ese momento tanto el Reglamento del Congreso como el del Parlamento de Andalucía iban a vivir existencias paralelas pero ya diferenciadas por sus propias experiencias y vicisitudes. No obstante, también ambos textos estaban llamados a experimentar una misma necesidad: la de salvar las dificultades de interpretación y las lagunas jurídicas que la práctica parlamentaria ponía regularmente de manifiesto mediante resoluciones presidenciales, instrumento éste previsto en casi todas las regulaciones reglamentarias. Así, varias de estas resoluciones de la Presidencia del Parlamento de Andalucía van a versar sobre algunos de los temas más típicamente conflictivos de la vida parlamentaria, tanto por su carácter recurrente como por su trascendencia cara a la correcta ordenación de la actividad política dentro de la Cámara: me refiero, por ejemplo, a la calificación de los escritos de enmienda presentados a los textos legislativos ${ }^{12}$, fuente permanente de discrepancias y controversias, como es de sobra conocido, en todas las mesas de las cámaras sin excepción. También se dictarían otras resoluciones necesarias para resolver conflictos políticos sobrevenidos con incidencia directa e inmediata en la organización política de la Cámara, como la relativa a la regulación del funcionamiento y organización del Grupo Mixto, y ello aunque su conformidad con los principios del propio Reglamento, que las resoluciones presidenciales no pueden contravenir, resultara dudosa ${ }^{13}$. Frente a este tipo de lagunas o pseudolagunas, también las resoluciones presidenciales se manifestarán como un instrumento idóneo para hacer frente a otros vacíos jurídicos sobrevenidos de carácter procedimental, a raíz de la creación y puesta en funcionamiento de nuevos órganos previstos en el Estatuto de Autonomía, como el Defensor del Pueblo Andaluz (art 46), o especialmente vinculados con el Parlamento de Andalucía, caso de la Cámara de Cuentas (creada por la Ley 1/1988, de 17 de marzo).

${ }^{10}$ Esta fuerzas políticas eran el Partido Socialista Obrero Español de Andalucía (PSOE-A), que obtuvo 66 escaños; la coalición formada por el Partido Popular, el Partido Demócrata Popular y la Unión Liberal (AP-PDP-UL), que obtuvo 17; la Unión de Centro Democrático (UCD), que obtuvo 15; el Partido Comunista de Andalucía (PCA-PCE), que obtuvo 8, y el Partido Socialista de Andalucía (PSA), que obtuvo 3.

${ }^{11}$ En esta II Legislatura desaparece la representación parlamentaria de la UCD, obteniendo el resto de las fuerza políticas el siguiente número de escaños: PSOE-A (60), AP-PDP-UL (28); Izquierda Unida-Convocatoria por Andalucía (coalición que incluía al PCA) (19), y PSA (2).

${ }^{12}$ Resolución de 1 de julio de 1987 (BOPA núm. 129, de 7 de julio de 1987).

13 Véase la Resolución de 23 de octubre de 1986 (BOPA núm. 18, de 30 de octubre de 1986). 
Ambas instituciones se relacionarán con el Parlamento a través de procedimientos específicos establecidos en estas resoluciones o en acuerdos de la propia Mesa de la Cámara $^{14}$.

Tras dos legislaturas completas con el Parlamento de Andalucía regido por un mismo texto reglamentario, pero con numerosas normas de organización y funcionamiento fuera del mismo, puede apreciarse la conformación de un sistema político andaluz configurado por cuatro fuerzas políticas: dos de ellos mayoritarias, el Partido Socialista Obrero Español de Andalucía (PSOE-A) y el Partido Popular de Andalucía (PP-A); y otras dos de representación mucho más reducida, reconocibles, aunque con diversas fórmulas electorales, en la formación Izquierda Unida-Convocatoria por Andalucía (IU-CA) y el Partido Andalucista (PA). Esta composición de la Cámara, con visos ya de permanencia en el tiempo, asentaría también una serie de prácticas en su funcionamiento que exigían un reconocimiento a nivel normativo. De ahí que en el transcurso de la III Legislatura (1990-1994) ${ }^{15}$, concretamente en abril de 1991, viera la luz, nueve años después de la aprobación del primero, el segundo Reglamento del Parlamento de Andalucía ${ }^{16}$. Además de las modificaciones técnicas exigidas por las circunstancias, como la integración en el cuerpo del Reglamento de la mayoría de las resoluciones presidenciales dictadas hasta entonces, o la incorporación de específicos procedimientos parlamentarios cuyo consolidación se pretendía (caso del debate general sobre el estado de la Comunidad Autónoma), el nuevo texto introduce algunas normas que reflejarán la existencia del que va a convertirse en uno de los referentes axiológicos más característicos del Parlamento andaluz: el pluralismo político, cuyo trasunto en el ámbito parlamentario consistirá esencialmente en la representación de todos los grupos parlamentarios de la Cámara en sus órganos de dirección. En este sentido, y con un efecto mucho más simbólico que real, el nuevo Reglamento contemplará la posibilidad de ampliar los cinco miembros de la Mesa (presidente, dos vicepresidentes y dos secretarios) con tantos vocales - sin derecho a voto- como grupos parlamentarios se hubieran constituido sin obtener en un primer momento presencia en aquella como consecuencia del resultado arrojado siguiendo el procedimiento de elección (arts. 35 y 37 ).

${ }^{14}$ Resolución, de 13 de marzo de 1986, sobre tramitación de los informes del Defensor del Pueblo Andaluz (BOPA núm. 361, de 14 de marzo de 1986), y Acuerdo de la Mesa del Parlamento de Andalucía, de 1 de febrero de 1989, sobre la elección de los miembros de la Cámara de Cuentas de Andalucía (BOPA núm. 265, de 10 de febrero de 1989).

${ }^{15}$ La representación en escaños de las fuerzas políticas en esta III Legislatura fue la siguiente: PSOE-A (62), PP-A (26), IU Los Verdes-CA (11) y PA (10).

${ }^{16}$ BOPA núm. 60, de 30 de abril de 1991. 


\section{LA DENOMINADA LEGISLATURA DE LA PINZA (1994- 1996): EL REGLAMENTO COMO GARANTE DE NUEVOS DERECHOS DE LOS AGENTES POLÍTICOS Y SOCIALES EN EL ÁMBITO PARLAMENTARIO}

Una alteración de primer orden en el sistema político andaluz condicionaría decisivamente sin embargo las expectativas de vigencia de este segundo Reglamento: el inicio de la IV Legislatura del Parlamento de Andalucía (1994-1996) con una composición en la que el PSOE-A perdía por primera vez la mayoría absoluta y en la que, aunque su grupo parlamentario seguirá siendo el más numeroso, iba a carecer desde un principio del apoyo de los demás grupos a derecha e izquierda, como lo demuestra el hecho de que el PP-A e IULV-CA unieran sus fuerzas en numerosas votaciones ${ }^{17}$. Precisamente por tal motivo dicha legislatura sería conocida como la de la pin$z a$, un gráfico término que aún hoy se utiliza para rememorarla al haber alcanzado gran eco en el imaginario político andaluz.

Una de las más importantes consecuencias de esta nueva conformación del Parlamento autonómico va a concernir precisamente al Reglamento de la Cámara, ya que su mayoría absoluta conjunta permitía a las dos últimas formaciones citadas acordar la reforma del mismo. En este contexto nacerá el tercer Reglamento del Parlamento de Andalucía ${ }^{18}$, que va a introducir numerosas novedades respecto del texto anterior bajo la influencia de principios ideológicos fácilmente reconocibles, pero también con la clara finalidad de favorecer de manera inmediata los intereses políticos de la oposición. Entre tales novedades destacan la potenciación de los mecanismos de control del ejecutivo por parte de los grupos parlamentarios, por un lado, y la apertura del Parlamento a la sociedad, mediante el establecimiento de algunos procedimientos de iniciativa o intervención ciudadana, por otro. De entrada, podemos destacar la introducción de una previsión pionera en el ámbito de las políticas de implementación de la igualdad de género que años después se han ido asentando en nuestro país con cierta naturalidad: la posibilidad de que, en los casos de embarazo o parto reciente, la diputada afectada pudiera ejercer su derecho al voto sin necesidad de estar presente en la Cámara, si bien limitado dicho derecho a los supuestos

${ }^{17}$ El número de escaños obtenido en esta IV Legislatura por cada formación política representada en la Cámara fue el siguiente: PSOE-A (45), PP-A (41), IULV-CA (20) y Coalición Andalucista-PA (3). Esta nuevo escenario político tuvo uno de sus primeros efectos en el procedimiento de investidura del Presidente de la Junta, la cual no se produjo hasta que el candidato del partido mayoritario (el diputado socialista Manuel Chaves González) obtuvo la mayoría simple en la tercera votación. No fue ajeno, sin embargo, a este resultado la no participación en esta última votación de los diputados de IULV-CA, salvo el Presidente de la Cámara, integrante de dicho grupo parlamentario, que se abstuvo.

${ }^{18}$ BOPA núm. 75, de 5 mayo de 1995. 
de votación pública por llamamiento (art. 86.2). Desde la perspectiva de las relaciones Parlamento-Consejo de Gobierno se puede mencionar, de manera muy señalada, el refuerzo del control político del segundo, al introducirse la nueva figura de las preguntas de interés general para la Comunidad Autónoma dirigidas al Presidente de la Junta de Andalucía (art. 159; actual 162). Por otra parte, se promueve la conexión directa de la institución parlamentaria con su contexto social a través de las comparecencias informativas de agentes sociales y organizaciones en el procedimiento legislativo, concretamente ante las comisiones (art. 113; actual 112), así como también la posibilidad de presentación al Consejo de Gobierno por parte de los diputados de preguntas orales de origen ciudadano (art. 162; actual 165).

Algún sector de la doctrina especializada ha destacado el papel de este Reglamento de 1995 en el proceso de formación de un derecho parlamentario propio de las comunidades autónomas ${ }^{19}$. Con todo, el prematuro aunque no menos previsible fin de esta peculiar IV Legislatura del Parlamento de Andalucía, tras la disolución anticipada de la Cámara por el Presidente de la Junta en enero de 1996, supondría un retorno a la normalidad del sistema parlamentario andaluz. En efecto, con la V Legislatura (1996-2000) el PSOE, si bien no alcanzaba tampoco la mayoría absoluta, reforzaba su posición con una mayor representación en la Cámara, además de asegurar, gracias al apoyo del PA, la gobernabilidad de la Comunidad Autónoma desde el ejecutivo ${ }^{20}$. Ni que decir tiene que las repercusiones desde el ámbito reglamentario no se harían esperar, siendo en los primeros meses de dicha legislatura objeto de reforma el Reglamento para introducir algunos ajustes en la regulación anterior ${ }^{21}$. No obstante, tal reforma no conllevaría ni mucho menos una regresión en los derechos de las minorías parlamentarias, algo imposible cuando, como era el caso, el grupo mayoritario carecía de la mayoría absoluta exigida por el propio Reglamento -con fundamento en el Estatuto de Autonomía (art. 27.2)- para operar cualquier modificación del mismo. Buena prueba de ello será la nueva ampliación del número de miembros de la Mesa de la Cámara, a la que se suman un vicepresidente y un secretario terceros (art. 27.2). De este modo, la representación de todos los grupos parlamentarios en la Mesa, que desde la III Legislatura se había garantizado mediante la

${ }^{19}$ En este sentido, J. Tudela Aranda: "La reforma del Reglamento de las Cortes de Aragón en el contexto del Parlamentarismo Autonómico". Revista Aragonesa de Administración Pública núm. 12, 1998, págs. 23-59. En efecto, según dicho autor, esta reforma, aun perteneciendo a una segunda generación de reglamentos parlamentarios autonómicos (como el propio Reglamento de las Cortes de Aragón de 1992 ó el de las Cortes Valencianas de 1994) que comenzaban ya a innovar sobre el modelo del Congreso de los Diputados, "es la primera en la que se encuentran gérmenes del nuevo modelo parlamentario" (págs. 32 a 38, en especial, pág. 37).

${ }^{20}$ La composición de la Cámara en esta V Legislatura fue la siguiente: PSOE-A (52 escaños), PP-A (40), IULV-CA (13) y PA (4).

${ }^{21}$ BOPA núm. 27, de 18 de julio de 1996. 
figura de los vocales, quedaba reforzada al exigirse ahora sobre sus miembros de pleno de derecho, desapareciendo en consecuencia aquellos (art. 37; actual art. 36). En cualquier caso, lo más llamativo de esta medida es que con ella se inicia una tendencia nada inhabitual en la práctica parlamentaria comparada, en el sentido de adaptar la composición de los órganos de dirección de las cámaras -y, en particular, sus mesas- a la concretamente resultante de los comicios electorales recién celebrados. Con el problema añadido, en el caso del Parlamento de Andalucía, de que esta regla consolidada en su Reglamento en aras del principio de pluralismo político estaba llamada a entrar en contradicción con el no menos asentado principio de correspondencia de la composición política de todos los órganos parlamentarios con la del Pleno ${ }^{22}$. Por otra parte, esta reforma será aprovechada también para modificar un extremo importante de la regulación de las preguntas de máxima actualidad (art. 158.3; actual art. 161.3), cuyos precedentes se remontan a la reforma reglamentaria de la III Legislatura $^{23}$, de modo que se amplía el plazo de los grupos parlamentarios para sustituir alguna de las preguntas incluidas en el orden del día del Pleno, originalmente fijado por la Mesa y la Junta de Portavoces con siete días de antelación, hasta un día antes del inicio de la sesión ${ }^{24}$. De este manera se consigue una mejor adaptación de este instrumento fundamental del control del ejecutivo a la agenda política realmente existente y generalmente marcada por la celebración de las sesiones del Consejo de Gobierno el martes por la mañana anterior a la sesión plenaria, que en el Parlamento de Andalucía se viene celebrando tradicionalmente miércoles por la tarde y jueves, mañana y tarde, en semanas alternas.

Aunque la próxima reforma general del Reglamento de la Cámara andaluza tendrá que esperar ya casi una década, llama la atención la apelación continuada a las resoluciones presidenciales para cubrir las deficiencias de interpretación o lagunas jurídicas detectadas en el Reglamento de 1995, incluso muy poco después de su refor-

${ }^{22}$ Esta contradicción se pondría cabalmente de manifiesto al comienzo de las VII y VIII Legislaturas, en las que, a través de una reforma reglamentaria cuya eficacia quedaba limitada a la duración de aquellas, hubo que crear nuevamente la figura de un vocal con voz pero sin voto, en ambos casos en favor del PP-A, dada la desproporción existente entre su número de diputados en el Pleno y su representación en la Mesa de la Cámara (Véase la nota 31). Con mayor virulencia ha vuelto a manifestarse este problema en la recién comenzada X Legislatura, en la que la composición inicial de la Mesa como consecuencia del procedimiento de elección de sus miembros establecido en el art. 34 RPA tuvo que ser modificada en aplicación de la regla establecida en el art. 36 (véase el DSPA núm. 1, de 16 de abril de 2015).

${ }^{23}$ Art. 153.2 RPA de 1991.

${ }^{24}$ Como se especificaba en el mencionado art. 158.3 (actual, aunque con alguna modificación, art. 161.3), la hora límite para la presentación de tales preguntas en el Registro de la Cámara pasa a ser de las diez horas del lunes establecida en el RPA de 1995 a las diecinueve horas del martes siempre de la misma semana de la sesión plenaria. 
ma. Tal modo de proceder puede explicarse desde luego como consecuencia de la aparición de situaciones de hecho inéditas hasta entonces que hacían oportuno y necesario acudir a dicho recurso de integración jurídica típicamente parlamentario. Pero, en parte, se debe también a uno de los principales males que suelen afectar a un momento tan importante para la vida de un Parlamento como es el de la elaboración de una norma del rango y entidad material de su Reglamento, que es, no lo olvidemos, el principal instrumento de autoorganización del órgano que ejerce el poder legislativo en cualquier sistema político. Me estoy refiriendo, claro está, a las premuras a las que suele estar sometida cualquier modificación reglamentaria una vez que la decisión de llevarla a cabo queda políticamente acordada, lo cual conlleva en muchos casos su tramitación apresurada sin dar tiempo suficiente ni a los servicios jurídicos de las cámaras ni a los propios parlamentarios a reflexionar de manera relativamente sosegada sobre los pormenores de la nueva regulación que se pretende introducir. De ahí que, en más ocasiones de las deseables, no tarden en ponerse de manifiesto deficiencias técnicas o lagunas en la nueva regulación que, con un poco más de tiempo de estudio y análisis preliminares, antes o durante la tramitación parlamentaria, podrían haberse evitado. Prueba de lo que decimos es justamente este Reglamento de 1995 que, tras sufrir una reforma transcurrido algo más de un año de su vigencia, tendría que ser completado nuevamente poco tiempo después con diversas resoluciones presidenciales en temas de tanta trascendencia parlamentaria como por ejemplo la calificación de los escritos de enmiendas presentados a textos legislativos ${ }^{25}$, el procedimiento de tramitación y enmienda del proyecto de ley de presupuestos ${ }^{26}$ o el procedimiento de adopción del acuerdo por parte de la Cámara de la interposición de recursos de inconstitucionalidad ${ }^{27}$.

\section{EL REGLAMENTO DE 2005: LA AFIRMACIÓN DE UN MO- DELO PARLAMENTARIO ANDALUZ Y SUS NUEVAS TEN- DENCIAS}

La composición política de la Cámara en la VI Legislatura (2000-2004) va a ser similar a la anterior, de modo que el Gobierno andaluz continuará disfrutando de una cómoda estabilidad política gracias al apoyo de su propio grupo parlamentario, el GPS, cercano nuevamente a la mayoría absoluta que completaría con el apoyo casi permanente del $\mathrm{GPA}^{28}$.

\footnotetext{
${ }^{25}$ Resolución de 29 de mayo de 1996 (BOPA núm. 16, de 7 de junio de 1996).

${ }^{26}$ Resolución de 19 de junio de 1996 (BOPA núm. 20, de 25 de junio de 1996).

${ }^{27}$ Resolución de 13 de junio de 1997 (BOPA núm. 120, de 20 de junio de 1997).

${ }^{28}$ La composición en la Cámara en esta VI Legislatura fue la siguiente: PSOE-A (52 escaños), PP-A (46), IULV-CA (6) y PA (5).
} 
Estos ocho años de estabilidad política parlamentaria constituirán un período idóneo para la consolidación de un cierto modelo parlamentario andaluz en el contexto de un sistema político caracterizado, como se ha apuntado ya, por una Cámara formada por cuatro grupos parlamentarios que no son sino el correlato de otras tantas fuerzas políticas que vienen obteniendo regularmente representación en la misma. Así, existen dos grupos mayoritarios (GPS y GPP-A) que se presentan abiertamente como alternativas de gobierno, aunque sólo el primero haya llegado efectivamente a ejercerlo; y otros dos minoritarios (GPIULV-CA y el GPA) que, aunque formalmente no renuncian a dicha aspiración, circunscriben su estrategia electoral y parlamentaria a resultar necesarios para la constitución de una mayoría política, ya sea mediante acuerdos puntuales o en un contexto temporal más amplio coincidente con el de la propia legislatura.

Es en este período, pues, cuando se asientan una serie de procedimientos y usos parlamentarios conformadores de un ordenamiento parlamentario andaluz que trasciende lo que es estrictamente el Reglamento de la Cámara, propiciando al mismo tiempo la previsibilidad de las actuaciones tanto de los órganos del Parlamento como de los agentes que actúan en su seno. Una circunstancia ésta de no poca relevancia cuando nos estamos refiriendo a un ámbito de la realidad material tan resistente a someterse a límites (y, por tanto, a juridificarse) como es la actividad política, de la que la actividad parlamentaria ha constituido tradicionalmente su representación más paradigmática.

En esta etapa de su historia a la que estamos haciendo referencia, el propio Parlamento de Andalucía puede ser una buena muestra de lo que aquí se dice, pues precisamente el periodo de estabilidad vivido en la V y VI Legislaturas con la constante puesta en práctica de los diversos procedimientos parlamentarios establecidos en el Reglamento permitirá detectar buena parte de las deficiencias y lagunas existentes en el mismo. De ellas, las más apremiantes serían colmadas de manera relativamente inmediata a través de resoluciones presidenciales, aunque al final la reforma general del propio Reglamento aparezca como la solución más idónea para adecuar el ordenamiento parlamentario a las demandas exigidas por la práctica de la Cámara casi un cuarto de siglo después de la constitución del primer Parlamento de Andalucía. Como anticipo, una modificación puntual del Reglamento se produciría al final de la VI Legislatura con la introducción de la figura del Diputado No adscrito, modificación a la que no resultó ajena la fractura previamente acaecida en el seno del GPA con el pase de dos de sus cinco diputados al Grupo Mixto ${ }^{29}$.

${ }^{29}$ BOPA núm. 615, de 7 de enero de 2004. El espíritu de dicha reforma viene sintetizado en el entonces novedoso art. 24.5 RPA, según el cual: "Los Diputados No Adscritos gozarán únicamente de los derechos reconocidos reglamentariamente a los Diputados individualmente considerados". 
Dicha reforma de alcance general comienza a gestarse a principios de la VII Legislatura (2004-2008) en la que el PSOE-A recupera la mayoría absoluta que había perdido una década antes ${ }^{30}$, si bien deberá esperar para ver la luz a su aprobación por el Pleno en septiembre de 2005. El resultado de la misma será el cuarto Reglamento del Parlamento de Andalucía, en el cual se introducen ya, siguiendo las nuevas tendencias del derecho parlamentario, una serie de institutos o procedimientos que se irán generalizando entre las distintas asambleas legislativas autonómicas del Estado, la mayoría de ellas también ya con un específico bagaje experimental sobre el que construir y consolidar sus propios modelos de régimen parlamentario ${ }^{31}$.

Como su extensa exposición de motivos expresamente reconoce, este nuevo Reglamento incorpora diversas modificaciones "de carácter axiológico que inciden directamente en los valores y principios que informan el régimen parlamentario andaluz". Así, el conjunto de nuevas aportaciones persigue dos claros objetivos: por un lado, el fortalecimiento de la posición del diputado en el ámbito parlamentario; y, sobre todo, por otro lado, el incremento y refuerzo de los instrumentos de control del ejecutivo. En cualquier caso, ambos tipos de medidas comparten el mismo principio rector, que no es otro que reforzar la posición del Parlamento a través de sus agentes principales, esto es, grupos parlamentarios y diputados, frente al Consejo de Gobierno, aunque sin afectar desde luego a la situación de cierta preeminencia de este último inherente al parlamentarismo racionalizado en el que desde un principio se inserta el régimen parlamentario andaluz.

${ }^{30}$ La composición en la Cámara en esta VII Legislatura fue la siguiente: PSOE-A (61 escaños), PP-A (37), IULV-CA (6) y PA (5).

${ }^{31}$ BOPA núm. 292, de 4 de octubre de 2005. No obstante, al principio de dicha legislatura se va a operar previamente una nueva reforma reglamentaria (BOPA núm. 8, de 19 de mayo de 2004) al objeto de introducir una disposición transitoria para recuperar la figura del vocal de la Mesa, si bien con una serie de cautelas formales como su eficacia temporal circunscrita a dicha legislatura y la necesidad para su efectivo establecimiento del acuerdo unánime de la Junta de Portavoces. El motivo de dicha reforma, al que ya hemos hecho referencia aquí, será nuevamente superar el conflicto entre el principio de correspondencia en la composición de los órganos de la Cámara con la del Pleno, por un lado, y el de representación de todos los grupos parlamentarios en aquellos, por otro. De este modo, el vocal sería nombrado por la Mesa a propuesta de grupo parlamentario afectado. A la vista de la composición de la Cámara indicada en la nota anterior, es evidente que la figura del vocal fue pensada para su cobertura por el GPP-A, que resultaba indiscutiblemente perjudicado por la conciliación de los dos principios mencionados. En efecto, la mayoría absoluta del PSOE-A en la Cámara se traducía en su representación mediante cuatro de los siete miembros de pleno derecho de la Mesa, de modo que los otros tres debían repartirse entre el resto de los grupos por igual a pesar de que el PP-A tenía seis veces más diputados que IULV-CA y el PA. Nuevamente al comienzo de la VIII Legislatura volvió a aprobarse con el mismo carácter idéntica disposición (BOPA núm. 10, de 2 de mayo de 2008), aunque esta vez no puede considerarse que tuviera igual justificación, dada la distinta composición del Pleno (véase la nota 55). 
Conforme a las pautas anteriores, un primer grupo de reformas afectan directamente a la posición de los parlamentarios tanto en relación con el ejecutivo como con la propia Cámara, de modo que dicha posición se refuerza con la modificación de diversos aspectos del Estatuto de los Diputados, tradicionalmente incluido con tal denominación en el Título I del Reglamento. Así, se recoge expresamente el derecho de los parlamentarios andaluces, en cuanto que miembros del máximo órgano representativo del pueblo andaluz, a un tratamiento institucional y protocolario preferente, en particular, en las actividades organizadas por la Administración pública andaluza (art. 6.3). Igualmente, se contempla por primera vez la posibilidad, en los términos que acuerde la Mesa de la Cámara, de que los diputados puedan percibir una asignación económica temporal al perder tal condición por extinción del mandato, o por renuncia, para permitir su adaptación a la vida laboral o administrativa (art. 8.1). Como contrapartida, se introducen también nuevas medidas de control de la actividad de los diputados en los órganos de la Cámara, caso de la publicación periódica por la Mesa del Parlamento de los datos relativos a la asistencia de sus miembros a las sesiones ya celebradas del Pleno y las comisiones de las que formen parte (art. 13.2). Asimismo, se establece una nueva regulación, más exigente, del Registro de Actividades, Bienes e Intereses de los diputados (heredero del Registro de Intereses ya establecido en el Reglamento de 1995), impulsando ahora su carácter público y su accesibilidad a través tanto de su publicación en los boletines oficiales como en Internet (art. 16).

Un segundo grupo de estas nuevas prescripciones reglamentarias afectan como se ha dicho al control parlamentario de la acción del Consejo de Gobierno. En este sentido se introduce, como una nueva facultad dentro del ejercicio del derecho de información de los diputados, la visita personal a dependencias de la Administración pública de la Junta de Andalucía (art. 7.5). Por el contrario, en relación con los tradicionales procedimientos de solicitud de información escrita o documental, se establecen dos cautelas: por un lado, que los datos solicitados sólo deberán facilitarse si su conocimiento no conculca las garantías legalmente establecidas para la protección de los datos de carácter personal (art. 7.1); y, por otro lado, aprovechando la mejor accesibilidad que permiten las nuevas tecnologías, que, cuando se trate de datos que constan en fuentes accesibles al público de carácter oficial, la Administración requerida podrá limitarse a la indicación precisa del lugar en el que se encuentren disponibles, siempre que sean susceptibles de reproducción (art. 7.2). De otra parte, una reivindicación unánime de los grupos parlamentarios de la oposición que va a tener también su acogida en el nuevo Reglamento es la facultad atribuida a cada grupo parlamentario para requerir directamente, sin que deba mediar ya acuerdo de la comisiones, la presencia ante estas de diversos responsables de los organismos autónomos, instituciones y empresas de la Junta de Andalucía, así como de otras entidades con personalidad jurídica propia distintas de los anteriores, en los que sea mayorita- 
ria la representación o participación directa, cualquiera que sea su forma, de la Junta (arts. 44.1.2. ${ }^{\circ}$ y 153.1$)^{32}$. Además, la función de control en comisión se refuerza con la posibilidad, contemplada en la Ley 6/2005, de 8 de abril, Reguladora de la Actividad Publicitaria de las Administraciones Públicas de Andalucía, de que la Mesa de la Cámara remita periódicamente a la comisión competente por razón de la materia la información que reciba del Consejo de Gobierno relativa a diversos extremos derivados de dicha Ley (art. 44.4) ${ }^{33}$. En la propia exposición de motivos se reconoce la imposibilidad de acometer en esta reforma la creación de una Oficina de Evaluación Legislativa, también reivindicada especialmente por los grupos de la minoría pero que se difiere a un momento posterior ${ }^{34}$. Por contra, se atribuye a la Oficina de Control Presupuestario, adscrita a la Secretaría General de la Cámara, una nueva función consistente en informar a los grupos parlamentarios y a los miembros de la comisión competente en materia de Hacienda sobre la documentación que se reciba en dicha comisión acerca de la aprobación y ejecución del Presupuesto, nivel de ejecución de las inversiones y aplicación y ejecución de los fondos europeos, así como sobre aquellos aspectos de la actividad parlamentaria que tengan repercusión en los ingresos y gastos públicos (art. 62.2. ${ }^{2}$ ). Por último, una de las modificaciones del Reglamento cuya puesta en práctica va a visualizarse con relativa frecuencia afecta a las comisiones de investigación sobre asuntos de interés público, ya que su creación puede ser solicitada ahora también por un sólo grupo parlamentario y no por dos como ocurría con anterioridad. Cumplido este requisito, se entenderá automáticamente constituida la comisión de investigación salvo que algún grupo parlamentario manifestase su oposición, en cuyo caso el asunto será debatido en el Pleno, creándose finalmente aquella si no se opone la mayoría de los miembros de la Cámara (art. 52.1 $)^{35}$.

32 En relación con esta nueva previsión reglamentaria fue necesario dictar con posterioridad una resolución interpretativa de la Presidencia de la Cámara, aclarando que la comparecencia de los citados responsables habría de tener lugar exclusivamente ante la comisión correspondiente y no en el Pleno [Resolución de 26 de noviembre de 2008 (BOPA núm. 130, de 3 de diciembre de 2008)].

${ }^{33}$ En concreto: " $1 .{ }^{\circ}$ Subvenciones a asociaciones, instituciones sin ánimo de lucro, empresas públicas y privadas y Corporaciones locales./ 2. ${ }^{\circ}$ Contratos públicos de la Administración autonómica, con especificación de los de asesoría externa./ 3. ${ }^{\circ}$ Relación de las adjudicaciones de los contratos, y de las ayudas, subvenciones y convenios previstos en la legislación en materia de actividad publicitaria./ 4. ${ }^{\circ}$ Planes de medios de los contratos de publicidad superiores a ciento veinte mil euros."

${ }^{34}$ Dicha oficina nunca ha llegado a regularse ni, por tanto, a constituirse.

35 Aún así, hasta el comienzo de la X Legislatura solo una comisión de investigación se ha llegado a constituir tras la modificación de este precepto, concretamente en la IX: la denominada "Comisión de Investigación sobre ayudas sociolaborales a trabajadores afectados por los ERE y a empresas en crisis otorgadas por la Administración de la Junta de Andalucía durante el período 20012010, ambos inclusive" (DSPA núm. 7, de 14 de junio de 2012; BOPA núm. 25, de 18 de junio de 2012). Su Dictamen, no obstante, fue rechazado por el Pleno (DSPA núm. 21, de 28 de noviembre de 2012; BOPA núm. 122, de 11 de diciembre de 2012). 
El nuevo Reglamento va a introducir también cambios en la regulación de los instrumentos parlamentarios típicos de control del ejecutivo, como son las interpelaciones y las preguntas. Así, por lo que a las primeras respecta se crea la figura de las interpelaciones sobre cuestiones de máxima actualidad o urgencia (art. 155.4), en un número además significativo (hasta ocho por cada período de sesiones), y ello con la confesada intención, así declarada en la exposición de motivos, de hacer "posible normativamente el siempre deseable acercamiento de esta importante figura de control al asunto de actualidad que motiva su formulación". De otra parte, por lo que atañe a las preguntas, el número de las que pueden ser formuladas por los diputados pertenecientes a los grupos parlamentarios de la oposición va a experimentar un aumento, ya que se restringen las preguntas formuladas por los diputados pertenecientes al grupo parlamentario con mayor número de miembros en la Cámara, las cuales no podrán alcanzar la mitad del total (art. 161.2.2. ${ }^{\circ}$ in fine). Dentro de la misma línea general que orienta la reforma reglamentaria en este ámbito de control del Consejo de Gobierno se incrementa también el número de preguntas de máxima actualidad que pueden formularse en el Pleno, al pasar de seis a ocho, y se garantiza además la inclusión en el orden del día de una para un diputado de cada grupo parlamentario (art. 161.3). En análogo sentido, se modifica el número y el régimen jurídico de las preguntas de interés general para la Comunidad Autónoma dirigidas al Presidente de la Junta de Andalucía, que pasan de las cuatro permitidas como máximo hasta entonces a un nuevo máximo coincidente con el de grupos parlamentarios constituidos en la Cámara, y sin que las mismas resulten computables, como venía ocurriendo, a efectos del límite máximo de veinticuatro preguntas previsto por el Reglamento para las dirigidas al Consejo de Gobierno (art. 162.1). Además se prevé la posibilidad de que tales preguntas se configuren como preguntas de máxima actualidad (art. 162.4).

Siempre en lo que a este serie de nuevas iniciativas relativas al control de la acción del Consejo de Gobierno respecta, un nuevo procedimiento introducido con esta reforma de 2005 va a despertar inicialmente no pocas expectativas cara a la práctica parlamentaria, aunque por el momento su utilización haya sido escasa: se trata de las preguntas de máxima actualidad en comisión (art. 163.4). Así, de acuerdo con la nueva regulación reglamentaria, en cada sesión de comisión, cumplidos determinados requisitos en el orden del día previamente aprobado ${ }^{36}$, un diputado de cada

\footnotetext{
${ }^{36}$ Concretamente, el Diputado debe contar con alguna pregunta ordinaria en dicho orden del día, teniendo como hora límite de presentación para la pregunta de máxima actualidad en comisión las diez horas del penúltimo día hábil anterior al de su celebración. Además, la inclusión de estas preguntas en el orden del día comporta para el Diputado beneficiado la obligación de retirar del inicialmente aprobado una pregunta ordinaria, a cuyo efecto el escrito en que se formule la iniciativa irá acompañado de la correspondiente propuesta de retirada.
} 
grupo parlamentario puede formular una pregunta que tenga por objeto cuestiones o temas de máxima actualidad, la cual se presentará por escrito ante la mesa de la comisión, que la calificará y dispondrá su inclusión en el orden del día de la sesión. En términos relativos, pocas han sido, sin embargo, como decimos, las ocasiones en que se ha hecho uso de esta facultad, que exige por otra parte la convocatoria urgente de una mesa a ese exclusivo fin al menos veinticuatro horas antes de la celebración de la sesión, lo cual plantea algunos problemas logísticos en una Comunidad Autónoma como la andaluza, cuya extensión territorial obliga a largos desplazamientos a muchos miembros de la Cámara. Finalmente, debe reseñarse la cautela establecida respecto de la tramitación de las preguntas escritas, al disponer el Reglamento, respecto de las no contestadas en plazo, que su inclusión en el orden del día de la siguiente sesión de la comisión competente para su contestación oral no relevará al Consejo de Gobierno de su deber de contestarlas por escrito, regulación esta mucho más conforme con lo que suele ser el contenido y finalidad de este tipo de preguntas (art 164.3).

Junto a estas medidas de refuerzo de la posición del Parlamento de Andalucía frente al Consejo de Gobierno que constituyen, como se ha dicho ya, el principio rector de la reforma de 2005, se aprovechó también la misma para introducir algunos retoques puntuales en el texto reglamentario que la práctica parlamentaria estaba exigiendo. Así, se ofrece la posibilidad de que grupos parlamentarios y diputados puedan presentar documentos por medios informáticos en el Registro General del Parlamento de acuerdo con las normas establecidas por la Mesa (art. 97.2). También se establece la prohibición de que las comisiones o sus mesas se reúnan los días de celebración de sesión del Pleno del Parlamento (art. 43.4), previsión ésta que intentaba, entre otros objetivos, evitar el absentismo en las sesiones plenarias por su coincidencia con otras convocatorias, pero que, por razones diversas, ha acabado siendo incumplida -al menos parcialmente- en la práctica ${ }^{37}$. Especial mención merece asimismo la previsión de que pueda utilizarse en los debates de la Cámara la lengua de signos española por aquellos intervinientes que lo necesitaren, los cuales estarán asistidos además de un intérprete (art. 76.2).

De otra parte, en algunos de los procedimientos parlamentarios más relevantes o de más frecuente utilización se introducen algunas puntuales modificaciones. Así ocurre, en efecto, con el debate de investidura (arts. 138.4 y 5) ${ }^{38}$. Y también con el

37 Y ello en el sentido de que las Mesas se siguen celebrando los días de Pleno, aunque no mientras se está celebrando la sesión plenaria.

${ }^{38}$ En concreto, se dispone la suspensión de la sesión hasta el día siguiente tras la conclusión de la intervención del candidato a la Presidencia de la Junta de Andalucía, así como la obligación de éste de contestar individualmente a cada uno de los diputados que intervengan. 
procedimiento de debate-tipo (art. 80) ${ }^{39}$, inspirado en el que en la práctica parlamentaria se venía utilizando para las proposiciones no de ley y cuya vocación de universalidad ha acabado extendiéndose al propio debate de totalidad de los proyectos de ley (art. 111), que no ha sido objeto de modificación alguna ${ }^{40}$. Igualmente se aprovecha la reforma para acelerar la tramitación de algunos otros procedimientos de empleo más inhabitual pero altamente sensibles, caso de la solicitud de reconsideración (art. 28.2) ${ }^{41}$, así como también, especialmente, el de aquellos que dependen de la acción del ejecutivo, como la contestación de las solicitudes de información o de las preguntas escritas formuladas por los diputados, o la manifestación del criterio del Consejo de Gobierno acerca de la toma en consideración de las proposiciones de ley presentadas en la Cámara (art. 95.2) ${ }^{42}$.

Ha de destacarse por último que con esta reforma se incorporan al texto articulado del Reglamento nueve de las trece resoluciones presidenciales en ese momento vigentes. La exposición de motivos explica tal decisión argumentado que "[d]e este

${ }^{39}$ Según dicho artículo, salvo disposición expresa en otro sentido todo debate se iniciará con una primera intervención del grupo parlamentario autor de la iniciativa, a la que seguirá el posicionamiento del resto de los grupos, cerrando el debate quien intervino en primer lugar y limitándose todos los tiempos de intervención a diez minutos. En cualquier caso, si varios grupos parlamentarios adujeran su derecho a iniciar el debate, la Presidencia decidirá con arreglo al criterio de mayor representación.

${ }^{40}$ Precisamente, respecto de las proposiciones no de ley, debe destacarse también, en línea con el refuerzo de la posición de las minorías que informa buena parte de la reforma de 2005, la sustitución de la exigencia de la unanimidad de todos los grupos parlamentarios por una mayoría de dos terceras partes de la Cámara o tres grupos parlamentarios que representen la mayoría de la misma, al objeto de poderse tramitar en el Pleno, y ser incluidas en un orden del día, aquellas que planteen propuestas de resolución a la Cámara para que ésta manifieste una determinada voluntad o emita una declaración política en relación con materias de competencia exclusiva del Estado o de la Administración Local (art. 171).

${ }^{41}$ Cuya tramitación se acelera al fijarse el plazo de formulación de dicha solicitud dentro de los dos días siguientes a la notificación del acuerdo que se pretende impugnar, debiendo resolver la Mesa -y esta es la gran novedad- en la primera sesión que celebre tras dicha formulación.

${ }^{42}$ En efecto, en todos estos supuestos no se suspenden los plazos impuestos al Consejo de Gobierno, excepción hecha del mes de agosto, aunque el Parlamento no celebre sesiones. De este modo, el RPA introducía una importante excepción al principio, hasta ahora generalmente compartido por los ordenamientos parlamentarios, por el que se suelen excluir del cómputo de los plazos los períodos en que el Parlamento no celebre sesiones, salvo que el asunto en cuestión estuviese incluido en el orden del día de una sesión extraordinaria. En cualquier caso, la inclusión del mes de julio dentro del segundo periodo ordinario de sesiones como consecuencia de la última reforma reglamentaria en noviembre de 2014 (véase Segunda Parte. V) ha vuelto a restablecer también para dichos supuestos dicho principio general. 
modo, se eleva a formal el rango reglamentario que materialmente venía reconociéndose a dichas resoluciones, como lo evidencia el hecho de que todas ellas hayan conservado su vigencia desde que fueron aprobadas". Una decisión esta que, sin embargo, abre de nuevo el debate acerca de si todas las normas materialmente parlamentarias o con incidencia puntual en los procedimientos parlamentarios deben incorporarse o no al cuerpo del Reglamento propiamente dicho ${ }^{43}$.

\section{SEGUNDA PARTE: LA CONSOLIDAGIÓN DEL SISTEMA PARLAMENTARIO ANDALUZ. EI REGLAMENTO DEL PARLAMENTO DE ANDALUGÍA A LA LUZ DEL NUEVO ESTATUTO DE AUTONOMÍA}

\section{EL MANTENIMIENTO DE LOS RASGOS ESENCIALES DEL RÉGIMEN PARLAMENTARIO ANDALUZ EN EL ESTATU- TO DE AUTONOMÍA DE 2007}

Una de las materias que menos cambios ha experimentado en los estatutos de autonomía aprobados en el nuevo siglo ha sido la relativa a la organización institucional. Tal circunstancia obedece seguramente a dos motivos fundamentales. En primer lugar, a la generalización en todos los estatutos -y no sólo en los aprobados por el procedimiento del art. $151 \mathrm{CE}$ - del régimen parlamentario contemplado de manera relativamente precisa en el art. $152 \mathrm{CE}$, que no es sino una proyección del régimen parlamentario estatal al ámbito autonómico. Y, en segundo lugar, a que este régimen parlamentario ha funcionado razonablemente bien en todas las comunidades autónomas; entre otros motivos porque ha entrado a formar parte de la cultura política de la España democrática, si bien es cierto que en los últimos años el actual modelo autonómico han empezado a ponerse en cuestión de manera abierta en aquellas co-

${ }^{43}$ Las cuatro resoluciones presidenciales que no se incorporaron al texto reglamentario fueron la Resolución de 29 de junio de 1992, por la que se regulaban determinados aspectos relativos a la publicación de distintos informes remitidos por la Cámara de Cuentas (BOPA núm. 185, de 10 de julio de 1992), la Resolución de 19 de junio de 1996, sobre normas que regulan la tramitación y enmienda del Proyecto de Ley de Presupuestos (BOPA núm. 20, de 25 de junio de 1996); la Resolución de 28 de mayo de 1997, por la que se establece el procedimiento de acceso del Parlamento de Andalucía al Registro de Intereses y Bienes de Altos Cargos de la Junta de Andalucía (BOPA núm. 116, de 6 de junio de 1997) y la Resolución de 18 de septiembre de 2002, reguladora del debate y aprobación del proyecto de revisión del Reglamento de Organización y Funcionamiento de la Cámara de Cuentas de Andalucía (BOPA núm. 386, de 3 de octubre de 2002). 
munidades autónomas que más problemas han venido teniendo históricamente con la inserción de sus subsistemas políticos dentro del sistema político estatal ${ }^{44}$.

Así las cosas, el nuevo Estatuto de Autonomía para Andalucía, aprobado por lo andaluces en referéndum el 18 de febrero de 2007 (Ley Orgánica 2/2007, de 19 de marzo) tampoco podía ser una excepción. En efecto, y a diferencia de lo que ocurre con otras materias estatutarias (competencias, derechos, relaciones institucionales...), la organización institucional de la Comunidad Autónoma regulada en el Título II del Estatuto de 1981 resulta absolutamente reconocible y por tanto comparable respecto a la de su homólogo: el Título IV del actual Estatuto. Además, las escasas modificaciones que se han producido apenas afectan a la organización del Parlamento de Andalucía, que permanece -como se acaba de decir- substancialmente inalterado, aunque sí a la configuración del régimen parlamentario. En este sentido, la dos nuevas previsiones estatutarias que, según era de prever, han incidido de manera evidente en el funcionamiento del sistema parlamentario andaluz tal y como lo hemos venido conociendo hasta entonces no tienen como destinatario al propio Parlamento sino al Consejo de Gobierno y, más en concreto, la primera de ellas, al Presidente o Presidenta de la Junta de Andalucía en un tema de tanta trascendencia como es el de su elección. Así, el Estatuto anterior establecía imperativamente la designación como Presidente de la Junta del candidato del partido que hubiere obtenido mayor número de escaños una vez transcurrido el plazo de dos meses a partir de la primera votación de investidura sin que ninguno de los propuestos hubiera obtenido el apoyo al menos de la mayoría simple de la Cámara (art. 37.3) ${ }^{45}$. Por el contrario, el nuevo Estatuto reproduce el trámite del procedimiento para la investidura del Presidente del Gobierno previsto en el art. 99.5 de la Constitución y dispone que, en tal supuesto, el Parlamento quedará automáticamente disuelto y el Presidente de la Jun-

${ }^{44}$ Me refiero, obviamente, a las comunidades autónomas de Euskadi y Cataluña. Así, una clara manifestación del cuestionamiento de ese modelo autonómico en el caso de la primera fue la Propuesta de Estatuto Político de la Comunidad de Euskadi, aprobada por el Parlamento Vasco el 30 de diciembre de 2004, que no superó el trámite de toma en consideración en el Congreso de los Diputados. En el caso de la segunda, la STC 31/2010, de 28 de junio, que anulaba varios artículos del Estatuto Autonomía de Cataluña de 2006 y reinterpretaba otros muchos, tuvo como reacción la Resolución del Parlamento de Cataluña 5/X, de 23 de enero de 2013, que aprobaba la Declaración de soberanía y del derecho a decidir del pueblo de Cataluña, o el Decreto del Presidente de la Generalitat de Cataluña 129/2014, de 27 de septiembre, de convocatoria de la consulta no referendaria sobre el futuro político de Cataluña (disposiciones ambas declaradas inconstitucionales, de manera parcial la primera y en su totalidad la segunda, por las SSTC 31 y 32/2015, de 25 de febrero, respectivamente).

${ }^{45}$ Supuesto este nunca verificado en la práctica, aunque estuvo a punto de hacerse realidad al comienzo de la IV Legislatura (véase nota 17). 
ta en funciones convocará nuevas elecciones (art. 118.3 in fine ${ }^{46}$. De otra parte, el Estatuto ahora vigente tomó nota de la que era posiblemente una de las más evidentes pseudolagunas de los regímenes políticos autonómicos, cuya regulación resultaba también una de las más demandadas por los sujetos políticos llamados a ejercer responsabilidades de gobierno en ellos: me refiero, lógicamente, al reconocimiento de la potestad del Consejo de Gobierno para dictar normas con fuerza de ley mediante la creación de una nueva categoría autonómica de fuentes del derecho como son los decretos legislativos (art. 109) y los decretos-leyes (art. 110). Una previsión esta que sin duda ha provocado sensibles alteraciones en las relaciones Parlamento-Consejo de Gobierno dentro del sistema parlamentario andaluz tal y como lo hemos conocido hasta ahora ${ }^{47}$.

Por el contrario, según se viene diciendo, las modificaciones estatutarias estrictamente atinentes a la organización institucional del Parlamento de Andalucía han sido de un alcance bastante menor. En realidad la única modificación susceptible de acabar teniendo cierta trascendencia, y que cada vez que se abría el debate de una posible reforma estatutaria se erigía en una de las reivindicaciones más significadas de las entonces dos formaciones políticas minoritarias con representación habitual en la Cámara andaluza, (IULV-CA y PA), ha sido la modificación del número de diputados que pueden integrar ésta. Así, se pasa de la horquilla de 90 a 110 prevista en el anterior Estatuto (art. 26.1) al mínimo de 109 que establece el actualmente vigente (art. 101.1), número éste que coincide con el que siempre ha tenido el Parlamento Andaluz desde su creación. También debe destacarse, en caso de terminación del mandato de cuatro años o de disolución de la Cámara, la prórroga del mismo para los diputados titulares y suplentes que integren la Diputación Permanente hasta la constitución de la nueva Cámara (art. 101.2).

\footnotetext{
46 También esta otra eventualidad permanece todavía inédita. No obstante, se especuló con ella en la actual legislatura ante la posibilidad de que la candidata a la Presidencia de la Junta de Andalucía, Susana Díaz, no fuera investida presidenta dentro del plazo establecido en el nuevo precepto estatutario, circunstancia que no se produjo al tener dicha investidura finalmente lugar en la cuarta votación (DSPA núm. 6, de 11 de junio de 2015).

${ }^{47}$ Así lo pone de manifiesto el número creciente de decretos-leyes expedidos por el Consejo de Gobierno desde la entrada en vigor del nuevo EAA: 15 en la VIII Legislatura (nueve tramitados como proyectos de ley) y 33 en la IX (dos tramitados como proyectos de ley).
} 


\section{LAS NUEVAS PREVISIONES ESTATUTARIAS GON INGI- DENCIA DIRECTA EN EL REGLAMENTO DEL PARLA- MENTO: SU PROGRESIVA INGORPORACIÓN AL ORDE- NAMIENTO PARLAMENTARIO MEDIANTE NORMAS IN- FRARREGLAMENTARIAS}

El limitado desarrollo con el que el Estatuto de Autonomía para Andalucía -tanto en su primera versión de 1981 (art. 27) como en la vigente de 2007 (art. 103)- aborda la organización y funcionamiento del Parlamento ha llevado a algún autor a destacar con razón, a propósito del nuevo texto estatutario, el papel del Reglamento en cuanto que auténtico soporte normativo de casi todos los aspectos organizativos y procedimentales de la Cámara andaluza ${ }^{48}$. De cualquier modo, y con independencia de su mayor o menor relevancia, sí debe no obstante hacerse mención a una serie de nuevas previsiones estatutarias que afectan inmediatamente a la institución parlamentaria y, en consecuencia, tienen que acabar incidiendo de manera directa en el Reglamento de la Cámara. Tales previsiones, que superan la veintena, son de distinta naturaleza y alcance ${ }^{49}$.

Así, un grupo de ellas constituyen nuevos mandatos o prescripciones con rango estatutario, como el de presencia equilibrada de hombres y mujeres en los nombramientos y designaciones de instituciones y órganos que corresponda efectuar al Parlamento de Andalucía (art. 107); o la existencia de leyes cuya aprobación exige mayoría cualificada (arts. 93.1; 96.4; 105.1), además de una votación final sobre el conjunto del texto (art. 108). A estas hay que añadir las derivadas de las relaciones del Parlamento de Andalucía con otras instituciones estatales a nivel orgánico, como ocurre con la designación de Senadores y Senadoras autonómicos (art. 106.17. ${ }^{\circ}$ ), cuya comparecencia ante la Cámara también se prevé (art 223); la participación en procesos de designación de miembros para formar parte de determinados órganos e instituciones del Estado (art. 87), integrar un órgano de nueva creación como es el Consejo de Justicia de Andalucía (art. 144.2) o dirigir otros entes de la propia Comunidad Autónoma, caso de la Radiotelevisión Pública Andaluza (art. 214.2). Por otra

${ }^{48}$ Véase el comentario de A. Porras Nadales sobre la forma de gobierno en Andalucía en S. Muñoz Machado-M. Rebollo Puig (dirs.): Comentarios al Estatuto de Autonomía para Andalucía, Thomson Civitas, Madrid, 2008, págs. 869-904, en especial, pág. 880.

${ }^{49}$ Dicha cantidad se deduce del informe preparatorio para una futura reforma del RPA realizado por los Servicios Jurídicos de la Cámara tras el encargo efectuado por el Letrado Mayor, a indicación de la Presidenta del Parlamento, poco después de la entrada en vigor del EAA, a fin de que fueran identificados tanto los extremos del RPA vigente que debían ser modificados como aquellos que debían ser objeto de nueva regulación. 
parte, ahora ya desde una perspectiva funcional, deben mencionarse también la recepción de la memoria anual de la Comisión Bilateral Junta de Andalucía-Estado (art. 220.3 in fine) o la consulta previa al Parlamento antes de la emisión del dictamen de las Cortes Generales sobre propuestas legislativas europeas en el marco del procedimiento de control de los principios de subsidiariedad y proporcionalidad que establezca el Derecho Comunitario (art. 237).

El resto de las modificaciones estatutarias en el estricto plano de la organización institucional del Parlamento se han limitado, en su mayor parte, a plasmar al más alto nivel normativo prescripciones que de hecho ya formaban parte de la realidad de la organización y el funcionamiento de la Cámara, mientras que otras han sido introducidas con la evidente finalidad de precisar o mejorar técnicamente algunos de los preceptos estatutarios en cuestiones relativas al derecho parlamentario. Así, entre las primeras, podemos mencionar la referencia expresa a Sevilla como sede del Parlamento de Andalucía (art. 4.1); el Estatuto del Diputado como materia reservada al Reglamento de la Cámara (at. 102.3); la determinación de los períodos ordinarios de sesiones y el régimen de convocatoria de sesiones extraordinarias (art. 103.3) ${ }^{50}$; la participación en el procedimiento legislativo de ciudadanos e instituciones $(30.1 \mathrm{~b}$ y $113)^{51}$; el examen y aprobación de la Cuenta General de la Comunidad Autónoma de Andalucía (art. 106.12. ${ }^{\circ}$ ); la presentación de las memorias anuales del Tribunal Superior de Justicia de Andalucía, de su Fiscalía y ahora también del Consejo de Justicia de Andalucía (arts. 143.3 y 5, y 144.4 h); la conformidad del Consejo de Go-

${ }^{50}$ Mientras que el anterior EAA se limitaba a indicar que los períodos ordinarios de sesiones comprendían cuatro meses y se celebrarían entre septiembre y diciembre, el primer período, y entre febrero y junio, el segundo (art. 27.4), el actual establece que los períodos ordinarios serán dos por año y durarán un total de ocho meses como mínimo, iniciándose el primero en septiembre y el segundo en febrero (art. 103.3). Igualmente, el régimen de convocatoria de las sesiones extraordinarias, regulado en el mismo precepto, experimenta una sustancial variación, ya que la misma, que corresponde al Presidente o Presidenta de la Cámara, habrá de ser aprobada previamente por la Diputación Permanente al menos en el caso en que dicha convocatoria se produzca a petición de los órganos o sujetos parlamentarios. Además la legitimación para solicitar dicha petición de convocatoria por parte del ejecutivo, que antes sólo se contemplaba respecto del Consejo de Gobierno, se amplía al Presidente de la Junta.

${ }^{51}$ En concreto, el art. 113 dice que "Los ciudadanos, a través de las organizaciones y asociaciones en que se integran, así como las instituciones, participarán en el procedimiento legislativo en los términos que establezca el Reglamento del Parlamento". De este modo, lo que en 1995 fue, como ya vimos, una importante innovación del ordenamiento parlamentario andaluz mediante la reforma del Reglamento de la Cámara, se ha convertido ahora en un mandato estatutario de obligada observancia [véase en tal sentido el comentario de A. Carmona Contreras sobre la elaboración de las normas autonómicas en M.J. Terol Becerra (dir): Comentarios al Estatuto de Autonomía para Andalucía, Tirant lo Blanch, Valencia, 2009, págs. 351]. 
bierno para la tramitación de toda proposición o enmienda que suponga un aumento de créditos o disminución de los ingresos presupuestarios (art. 190.1); o el control de los medios de comunicación social gestionados directamente por la Junta de Andalucía (art. 214.1).

De otra parte, ahora ya con el principal objeto de precisar el significado o mejorar técnicamente la redacción de preceptos que ya existían en el primer Estatuto, se puede citar también la referencia a la plena autonomía presupuestaria, administrativa y disciplinaria del Parlamento (art. 102.1 y 4); la solicitud al Estado de la atribución, transferencia o delegación de facultades ex art. 150.1 y 2 de la Constitución (art. 106.18. ${ }^{\circ}$ ); el procedimiento para la exigencia de responsabilidad política a través de la moción de censura, referida ya sólo al Consejo de Gobierno y no al Presidente de la Junta (art. 126.1); la alusión a mecanismos de control y seguimiento de lo acordado en los convenios de la Comunidad Autónoma de Andalucía con otras comunidades autónomas para la gestión y prestación conjunta de servicios propios de las mismas (art. 226.1 in fine); o las modificaciones introducidas en el procedimiento de reforma estatutaria, señaladamente la modificación de la mayoría cualificada para la aprobación de la propuesta de reforma por el Parlamento de Andalucía, que pasa de tres quintos a dos tercios (art. 248.1 b), así como la introducción del procedimiento de retirada por el Parlamento de dicha propuesta durante su tramitación por las Cortes Generales (art. 250).

Lógicamente, con la entrada en vigor del nuevo Estatuto se hace evidente la necesidad de introducir numerosas modificaciones en el Reglamento de la Cámara para adaptarlo a las disposiciones anteriormente mencionadas. Sin embargo, la primera y única reforma del Reglamento directamente relacionada con la entrada en vigor del nuevo texto estatutario va a consistir en la renumeración de las remisiones que en el mismo se hacían al anterior Estatuto para hacerlas corresponder con el articulado del recién aprobado, y ello aprovechando la reforma reglamentaria efectuada para adaptar su redacción a un uso no sexista del lenguaje ${ }^{52}$. Descartada, pues, una reforma inminente por falta de consenso político al respecto, y encontrándose la VII Legislatura en su recta final, se afrontan sin embargo algunos vacíos de tipo procedimental que progresivamente se van poniendo de manifiesto mediante el recurso a las resoluciones de la Presidencia, las cuales, como indica el Reglamento, cuando se dictan para suplir lagunas en el mismo con carácter general deben contar con el parecer favorable de la Mesa y de la Junta de Portavoces (art. 29.2. ${ }^{\circ}$ ).

\footnotetext{
${ }^{52}$ BOPA núm. 768, de 27 de noviembre de 2007.
} 
Precisamente, y sin que quepa descartar por completo el simbolismo de la elección, la primera de estas resoluciones es la relativa a la adecuación de los nombramientos y designaciones que efectúe el Parlamento de Andalucía al principio de presencia equilibrada de hombres y mujeres ${ }^{53}$. Acogiendo la definición de dicho concepto contenida en la disposición adicional primera de la Ley Orgánica 3/2007, de 22 de marzo, para la igualdad efectiva de mujeres y hombres, la citada resolución entiende por "presencia equilibrada" aquella en la que, en el conjunto a que se refiera, el número de personas de cada sexo no supere el $60 \%$ ni se encuentre representado en menos del $40 \%$, resultando aplicable el citado principio "a todos los nombramientos y designaciones de miembros de instituciones y órganos que corresponda realizar al Parlamento de Andalucía, sean éstos o no íntegramente de extracción parlamentaria, se produzcan por vez primera o sean como consecuencia de una renovación total o una mera sustitución parcial de dichos miembros" (apartado primero). Uno de los extremos de su regulación llamado a originar algunos conflictos es aquel en virtud del cual, en el supuesto de propuestas que impidan de manera individual o en conjunto con el resto la consecución de dicho objetivo en las instituciones u órganos de que se trate, la Mesa del Parlamento podrá suspender la tramitación de las mismas hasta verificar, a la vista del resto de las propuestas que deban presentarse, su adecuación a los criterios anteriormente indicados (apartado segundo). En efecto, dicha previsión obliga en aquellos nombramientos o designaciones que han de hacerse conjuntamente por todos los grupos parlamentarios a un acuerdo entre los mismos para asegurar el referido equilibrio entre sexos. Sin embargo, dicho acuerdo no ha sido siempre fácil de alcanzar, produciéndose en más de una ocasión el bloqueo del correspondiente procedimiento ${ }^{54}$.

En la siguiente legislatura, la VIII, el PSOE mantuvo la mayoría absoluta, aunque la más importante novedad fue sin duda la ausencia total de representación del PA por primera vez en la historia del Parlamento andaluz ${ }^{55}$. Sin embargo, al no exis-

${ }^{53}$ Resolución, de 28 de marzo de 2007 (BOPA núm. 634, de 30 de marzo).

${ }^{54}$ Así ocurrió, en efecto, la última vez que se llevó a cabo la designación de cuatros adjuntos por el Defensor del Pueblo Andaluz (DSCB 64/VII Legislatura, de 20 de junio de 2007), cuya sujeción al mandato establecido en el art. 107 EAA resultaba cuanto menos dudosa conforme al tenor del la Ley reguladora de dicha institución (art. 8.2). Pero mayor controversia suscitó aún, como se verá más adelante, la designación de dos candidatos a magistrados del Tribunal Constitucional a propuesta del Parlamento de Andalucía (ver nota 66). Por otra parte, y como indica la disposición adicional de dicha resolución, el principio de presencia o composición equilibrada de hombres y mujeres resulta de aplicación a la Mesa del Parlamento de Andalucía, mientras que en las comisiones y en sus respectivas mesas el cómputo de presencia de cada uno de los sexos se realizará tomando en cuenta su representación respectiva en el conjunto de comisiones y mesas de la Cámara.

${ }^{55}$ La composición del Parlamento de Andalucía en la VIII Legislatura, en número de escaños, fue la siguiente: PSOE-A (56), PP-A (47) e IULV-CA (6). 
tir consenso suficiente de los tres grupos parlamentarios existentes en apoyo de una reforma del Reglamento, las necesarias regulaciones parlamentarias derivadas de los preceptos estatutarios han seguido llevándose acabo por la vía de las resoluciones presidenciales o de otras normas de carácter infrarreglamentario como las "disposiciones complementarias" de los preceptos legales reguladores del nombramiento, elección o designación de personas por el Pleno, previstas en el 182.2..$^{\circ}$ del Reglamento ${ }^{56}$.

Así, la primera resolución de la Presidencia en la recién estrenada legislatura relacionada con las nuevas previsiones estatutarias ha sido la atinente a la designación por el Parlamento de los senadores en representación de la Comunidad Autónoma, que ponía de manifiesto la insuficiencia de la regulación del procedimiento de elección de los mismos previstas en el Reglamento (art. 180) ${ }^{57}$. Esta resolución tiene en cuenta no sólo las disposiciones estatutarias que regulan específicamente la elección de tales senadores (arts. 103.4 y 106.17. ${ }^{\circ}$ ), sino también el principio de presencia equilibrada de ambos sexos en los nombramientos y designaciones que corresponda efectuar a la Cámara andaluza (art. 107, ya citado), todo ello en concordancia además con la regulación general de dicho procedimiento de designación contenida en la Ley 19/2007, de 17 de diciembre, de designación de Senadores y Senadoras en representación de la Comunidad Autónoma de Andalucía.

Asimismo deben citarse entre las resoluciones presidenciales aprobadas las dos relativas al control por el Parlamento de los Decretos-Leyes y de la legislación delegada proveniente del Consejo de Gobierno ${ }^{58}$. En realidad, ambas resoluciones siguen muy de cerca la regulación del Reglamento del Congreso de los Diputados sobre la materia, aunque en la relativa a la legislación delegada sí cabe apreciar algunas singularidades, consecuencia a su vez de la peculiar regulación que de dicha legislación delegada hace el Estatuto de Autonomía (art. 109) respecto a la de la Constitución y demás estatutos de autonomía que han incluido dicha categoría normativa en su sistema de fuentes ${ }^{59}$.

${ }^{56}$ Conforme a dicho precepto, tales disposiciones han de ser dictadas por la Mesa de la Cámara, contando con el acuerdo de la Junta de Portavoces, adoptado por mayoría al menos de tres quintos.

${ }^{57}$ Resolución de 9 de abril de 2008 (BOPA núm. 3, de 16 de abril de 2008).

58 Resoluciones de 5 de junio de 2008 (BOPA núm. 29, de 6 de junio de 2008), y de 16 de abril de 2009 (BOPA núm. 226, de 29 de abril de 2009), respectivamente.

${ }^{59}$ En efecto, como pone de manifiesto la propia exposición de motivos de la Resolución sobre control por el Parlamento de la legislación delegada aprobada por el Consejo de Gobierno, el art. 109 EAA sólo prevé formas adicionales de control, además de las jurisdiccionales, en el supuesto de la delegación legislativa otorgada mediante una ley de bases para la formación de textos articulados (apartado 3), no en el caso de la otorgada mediante ley ordinaria para la refundición de los mismos (apartado 4). 
Por su parte, entre las disposiciones complementarias ha de hacerse en primer lugar mención a la relativa a la elección de Presidente o Presidenta del Consejo de Administración de la Agencia Pública Empresarial de la Radio y Televisión de Andalucía (RTVA) ${ }^{60}$, elección atribuida por el Estatuto de Autonomía al Parlamento de Andalucía, que deberá elegir a su titular por mayoría cualificada (art. 214.2), y regulada en la ley autonómica relativa al citado ente ${ }^{61}$.

Pero indudable relevancia tiene también otra de estas disposiciones complementarias, concretamente la relativa a la presentación por el Parlamento de candidatos a Magistrado o Magistrada del Tribunal Constitucional a proponer por el Senado ${ }^{62}$. Aunque amparada en el art. 224 del Estatuto, esta nueva atribución a los parlamentos autonómicos es consecuencia directa de la reforma de la Ley Orgánica del Tribuna Constitucional por la Ley Orgánica 6/2007, de 24 de mayo, así como también, a raíz de esta, de la reforma del Reglamento del Senado en noviembre de $2007^{63}$. Así, el art. 16.1 de dicha Ley Orgánica dispone, tras su nueva redacción, que "Los Magistrados propuestos por el Senado serán elegidos entre los candidatos presentados por las Asambleas Legislativas de las Comunidades Autónomas en los términos que determine el Reglamento de la Cámara”. Por su parte, el artículo 184.7 a) del Reglamento del Senado prevé, también tras su nueva redacción, que el Presidente del Senado comunique a los presidentes de las asambleas legislativas de las comunidades autónomas la apertura de un plazo para la presentación de las candidaturas dentro del cual cada asamblea legislativa podrá presentar hasta dos candidatos, que deberán cumplir los requisitos exigidos por la Constitución y las leyes para desempeñar el cargo ${ }^{64}$.

\footnotetext{
${ }^{60}$ Acuerdo de la Mesa del Parlamento de 21 de mayo de 2008 (BOPA núm. 20, de 23 de mayo de 2008).

${ }^{61}$ Ley 18/2007, de 17 de diciembre. Su art. 18.1 establece que la persona titular de la Dirección General de la RTVA será elegida por el Pleno del Parlamento de Andalucía por mayoría de dos tercios y, en el caso de no alcanzarse la citada mayoría en primera votación, será elegida por mayoría de tres quintos. En la VII Legislatura ya habían sido aprobadas también unas disposiciones complementarias sobre la elección de los miembros del Consejo Audiovisual de Andalucía (BOPA núm. 201, de 19 de mayo de 2005), atribuida por el art. 5 de la Ley 1/2004, de 17 de diciembre, reguladora de dicho órgano, al Parlamento de Andalucía.

${ }^{62}$ Acuerdo de la Mesa del Parlamento de 10 de septiembre de 2008 (BOPA núm. 72, de 11 de septiembre de 2008).

${ }^{63}$ BOE núm. 284, de 27 de noviembre de 2007.

${ }^{64}$ La constitucionalidad de ambas reformas, muy cuestionadas por diversos sectores de la doctrina, fue avalada, aunque con algunos votos particulares, por el Tribunal Constitucional en las SSTC 49/2008, de 9 de abril, y 101/208, de 24 de julio, respectivamente. Las reservas expresadas por el Tribunal respecto al nuevo tenor del art. 16.1 de la Ley Orgánica en la primera de dichas sentencias desembocaron en un fallo interpretativo del correspondiente precepto del Reglamento del Senado en la segunda.
} 
Pues bien, efectuada la preceptiva comunicación por parte del Presidente del Senado a la Presidenta del Parlamento de Andalucía de la apertura del plazo de presentación de candidaturas para la próxima renovación de magistrados del Tribunal Constitucional, resultaba ineludible complementar la regulación establecida en ambas normas para el conjunto de las cámaras autonómicas, señaladamente en lo relativo al procedimiento de presentación de tales candidaturas y a la fórmula de sufragio a seguir en relación con la propuesta o propuestas realizadas. En tal sentido, debe destacarse que, partiendo del procedimiento establecido en el art. 92.1 y 2 del Reglamento ${ }^{65}$, estas disposiciones complementarias atribuyen a los grupos parlamentarios la iniciativa para proponer de manera individual o conjunta hasta un máximo de dos candidatos, los cuales deberán reunir los requisitos de idoneidad establecidos en la Ley Orgánica del Tribunal Constitucional (art. 18). Verificados por la Mesa el cumplimiento de estos requisitos y los demás que fueran jurídicamente exigibles (entre ellos el de la presencia equilibrada por sexos en los términos de la Resolución de la Presidencia de la Cámara de 28 de marzo de 2007), tiene lugar la convocatoria de la correspondiente sesión plenaria para efectuar las designaciones. A tal efecto los diputados pueden proponer un solo candidato o candidata resultando designados los dos candidatos que hubieran obtenido mayor número de votos. Ahora bien, como consecuencia del principio de presencia equilibrada, en dichas disposiciones complementarias se prevé también que "en el caso de que ambos candidatos fueran del mismo sexo, la segunda propuesta recaerá en la siguiente persona más votada de sexo distinto a quien hubiera resultado designada en primer lugar" (disposición quinta d). De hecho, esta regla tuvo que ser aplicada en la primera y única designación de candidatos a magistrados del Tribunal Constitucional celebrada hasta ahora en la Cámara andaluza ${ }^{66}$.

\section{UNA MEDIDA PIONERA EN EL SISTEMA PARLAMENTA- RIO ESPAÑOL: LA DELEGACIÓN DEL VOTO}

Como se ha dicho ya, la primera cámara legislativa que contempló la posibilidad del voto parlamentario no presencial en España fue el Parlamento de Andalucía, tras la reforma de su Reglamento en 1995. No obstante, esta modalidad de voto no fue nunca aplicada al no verificarse las circunstancias contempladas en el entonces vigente art. 86.2 que habilitaban su ejercicio y que eran -recordemos- la imposibilidad

${ }^{65} \mathrm{Al}$ tratarse de elección de personas, votación secreta mediante papeletas siendo los diputados llamados nominalmente a la Mesa para depositarlas en la urna correspondiente.

${ }^{66}$ En efecto, los dos candidatos que resultaron más votados, propuestos por el GPS y el GPP-A eran hombres, de modo que la segunda propuesta de la Cámara recayó finalmente, en detrimento de la de este último grupo, en la candidata propuesta por el GPIULV-CA, quien había obtenido un respaldo parlamentario mucho menor (DSPA Plenos 17, de 25 de septiembre de 2008). 
de asistencia de una diputada a una sesión plenaria por causa de embarazo o parto reciente con motivo de su participación en una votación pública por llamamiento.

Desde entonces, y en un primer contexto de progresiva incorporación de la mujer a los espacios públicos no sólo sociales sino también políticos, han sido varias las asambleas autonómicas que han reformado sus reglamentos para incorporar modalidades de voto distintas a las estrictamente presenciales ${ }^{67}$. En cualquier caso, la regulación existente dista mucho de ser homogénea tanto en lo que se refiere a los supuestos que habilitan para el voto no presencial, que han superado ya ese contexto inicial al que hacíamos referencia, como en lo que atañe al concreto procedimiento de emisión del voto. Así, entre los supuestos que habilitan para la emisión por parte de los parlamentarios del voto por un procedimiento no presencial se contempla, además de la situación de embarazo o parto de la mujer, el permiso parental (bajo diversas formulaciones), la adopción, la hospitalización o convalecencia y los procesos de larga enfermedad ${ }^{68}$. De otra parte, los tipos de procedimiento para la emisión del voto no presencial suelen restringirse a las sesiones plenarias e incluso a la votación pública o por llamamiento (procedimientos de investidura, moción de censura y cuestión de confianza ${ }^{69}$. A tal fin se prevé la delegación del voto en otro diputado o diputada o en el portavoz de su grupo parlamentario, mediante un trámite aparentemente sencillo ante la Mesa de la Cámara ${ }^{70}$, así como también la eventual habilitación de un sistema de videoconferencia u otros procedimientos técnicos ${ }^{71}$.

67 Estas modalidades tradicionales de voto presencial son básicamente cuatro: por asentimiento, ordinaria (ya sea en su expresión más clásica, levantándose los diputados del escaño o alzando la mano, o moderna, por sistema electrónico), pública por llamamiento y secreta (mediante bolas o papeletas). Casi todas ellas se encuentran contempladas todavía hoy en la práctica totalidad de los reglamentos parlamentarios de nuestro país (véase al respecto los arts. 88 y ss. RPA).

68 Véanse al respecto los reglamentos del Parlamento de Canarias (art. 98.2); Cortes Valencianas (art. 81.5.'); Parlamento de Cataluña (art. 84); Asamblea de Extremadura (art. 142), Parlamento de Navarra (art. 94.2) y Parlamento Vasco (art. 89.1).

69 Caso este último del Reglamento del Parlamento de Canarias. Por contra, en el caso del Reglamento de la Asamblea de Extremadura la delegación del voto es general, esto es, no circunscrita al Pleno.

70 Véanse los Reglamentos del Parlamento de Cataluña y del Parlamento Vasco.

71 Así se contempla en los Reglamentos de la Asamblea de Extremadura y de las Cortes Valencianas. De hecho, un procedimiento de voto telemático se puso efectivamente en práctica en esta última cámara para facilitar las votaciones de una diputada en situación de baja por maternidad con motivo del debate final del proyecto de Ley de Presupuestos de la Generalidad Valenciana para el año 2009, así como del correspondiente proyecto de Ley de acompañamiento. Dicha experiencia puso de manifiesto las dificultades que existen todavía para organizar técnicamente votaciones al menos cuando se trata de trámites parlamentarios tan complejos como el indicado, que incluía la votación de cerca de tres mil enmiendas (véase al respecto, J. Sevilla Merino: "El voto no presencial de sus señorías", La Ley, núm. 7110, de 9 de febrero de 2009, págs. 1-6, en especial pág. 5). 
En el derecho comparado internacional, y abstracción hecha de la paulatina implantación de procedimientos de votación por sistemas telemáticos que se antojan inevitables junto a la delegación del voto ${ }^{72}$, se contempla también a nivel constitucional la sustitución, incluso temporal, de los miembros de las cámaras ${ }^{73}$. En España, además de en el ámbito autonómico, también se ha suscitado la cuestión en relación con las propias Cortes Generales, decantándose finalmente el Congreso de los Diputados y posteriormente el Senado por acoger en sus respectivos reglamentos la posibilidad del voto telemático por parte de sus miembros en las sesiones plenarias, aunque con no pocas restricciones y cautelas ${ }^{74}$.

Según hemos visto, en el caso de las asambleas autonómicas todas las posibles opciones de sistemas de voto no presencial resultan en principio factibles, ya que, salvo algunas excepciones como las de los estatutos de autonomía de Cantabria (art. 12.3 in fine), Murcia (art. 26.5), La Rioja (art. 18.8) o las Islas Baleares (art. 44.2), en el resto el carácter personal e indelegable del voto parlamentario se encuentra recogido a lo sumo en los propios reglamentos parlamentarios. Ciertamente, desde algunos sectores doctrinales se ha intentado extender el alcance de la personalidad e indelegabilidad del voto de los miembros de la Cortes Generales a los de los parlamentos de las comunidades autónomas por considerarlo un principio fundamental de nuestro sistema parlamentario no sólo a nivel estatal sino también, implícitamente, a nivel autonómico (art. 152.1 CE), consecuente además con la prohibición del mandato imperativo, que sí se reconoce en los estatutos de autonomía y ha sido integrada desde un principio por el Tribunal Constitucional en el contenido del derecho fundamen-

${ }^{72}$ Como es sabido, uno de los ejemplos más representativos de delegación del voto es el del Parlamento francés (véase el art. 27 de la Constitución de 4 de octubre de 1958, desarrollado por la $\mathrm{Or}$ denanza núm. 58-1066, de 7 de noviembre de 1958, relativa a la ley orgánica por la que se autoriza excepcionalmente a los parlamentarios la delegación de su derecho de voto).

73 Caso de Suecia (art. 9, del Cap. III y art. 9 del Cap. IV del Instrumento de Gobierno); Dinamarca (art. 31.4 de la Constitución); o Portugal (art. 153.2 de la Constitución). Sobre este tema del voto no presencial en relación con sus concretas posibilidades de aplicación en el Parlamento de Andalucía puede consultarse el trabajo de J. Terrón Montero: "La ausencia temporal del diputado por motivos relevantes: posibles soluciones", en J. Cano Bueso (coord.): El Parlamento de Andalucía. Órganos de extracción parlamentaria. Órganos consultivos o de participación de designación parlamentaria. Jornadas de Estudio Organizadas por el Parlamento de Andalucía. XX Aniversario del Estatuto. Parlamento de Andalucía, Comares, Granada, 2004 (págs. 177-199).

${ }^{74}$ Arts. 82.2 y 92.3, respectivamente (véase al respecto: F. Santaolalla López: Derecho Parlamentario Español, Madrid, Dykinson, 2013, pág. 254). Al parecer, también se elaboró un informe técnico encargado en su momento por el Ministerio de Igualdad que, sin descartar el voto telemático, abogaba por el procedimiento de la sustitución temporal (que exigía la reforma de la LOREG), dada la consideración expresa del voto de los diputados y senadores como personal e indelegable en el art. 79.3 CE (véase el diario El País de 19 de junio de 2009; concretamente, el informe fue encargado al Observatorio de Derecho europeo, autonómico y local de la Universidad de Granada). 
tal a la participación política (art. $23 \mathrm{CE})^{75}$. Sin embargo, estas tesis resultan muy discutibles desde su propio presupuesto ${ }^{76}$, además de que al menos la primera de ellas no se corresponde con la doctrina del Tribunal Constitucional, que en un asunto análogo afirmó hace ya tiempo que "no es en modo alguno exigible, en virtud de los mandatos constitucionales, que las instituciones legislativas de las Comunidades Autónomas deban adecuar su estructura, funcionamiento u organización a las correspondientes de las Cortes Generales, ni que deban aplicarse a las cámaras legislativas de las Comunidades Autónomas, en forma directa o supletoria, las normas constitucionales que regulen la organización y funcionamiento de las Cortes Generales (...) (STG 179/1989, FJ 6). Por otra parte, debería tenerse en cuenta también que la prohibición del mandato imperativo se ha venido tradicionalmente entendiendo en el contexto de las relaciones entre electores y elegidos, no en el de las relaciones de estos últimos entre sí.

Aunque el tema ya se había estado valorando desde algún tiempo antes, la necesidad de incorporar en el Reglamento del Parlamento de Andalucía alguna previsión relativa al voto no presencial se suscitaría con cierta urgencia a raíz de una circunstancia ocurrida en una sesión plenaria con motivo de un debate general sobre las repercusiones para Andalucía del proyecto de Ley de Presupuestos Generales del Estado para 2009: se trata del rechazo, como consecuencia de un empate en la votación, de unas propuestas de resolución formuladas por el GPS, mayoritario en la Cámara, a raíz de la ausencia, entre otras, de tres de sus diputadas: una de ellas a punto de dar a luz, otra fuera del país efectuando unos trámites de adopción y una tercera aquejada de una grave enfermedad ${ }^{77}$.

Seguramente esta diversidad de supuestos concurrentes como causa impeditiva del voto personal no fuera ajena al contenido de la proposición de ley de reforma del art. 85 del Reglamento presentada pocos meses después por el propio GPS "para facilitar las votaciones en los casos de maternidad o/y paternidad y en supuestos de enfermedad" según se hacía constar en el mismo título. La modalidad que se contemplaba en esta iniciativa no era otra que la delegación del voto en las sesiones plenarias, aunque abriéndose también la posibilidad de ejercer el mismo de forma telemática ${ }^{78}$.

75 Véase al respecto STC 10/1983, de 21 de febrero.

76 De entrada, no habría que pasar por alto, conforme al art. 151.2 CE, que el régimen parlamentario sólo es una exigencia constitucional para las asambleas legislativas de las Comunidades Autónomas que accedieron a la autonomía por el procedimiento previsto en el art. 151 de la Constitución.

77 DSPA Pleno núm. 19, de 9 de octubre de 2008.

${ }^{78}$ BOPA núm. 189, de 4 de marzo de 2009. 
La necesidad de contemplar este tipo de procedimiento se justificaba en la exposición de motivos de la proposición de reforma en una consideración general de mención no por recurrente menos justificada, como es la histórica postergación de la mujer en todos los ámbitos de la vida pública incluido también el político. Pero, asimismo, se hacía referencia a otra circunstancia más concreta y particular, aunque no exclusiva, que ya venía caracterizando al Parlamento andaluz: el considerable número de diputadas que integraban la Cámara, superior al cuarenta por ciento, consecuencia directa de la reforma de la Ley Electoral de Andalucía en el año 2005 con la introducción -de manera obligatoria para todas las formaciones políticas concurrentes a las elecciones autonómicas- de listas paritarias tipo cremallera, que alternan candidatos de uno y otro sexo. ${ }^{79}$

Tras ser tomada en consideración por el Pleno ${ }^{80}$, la proposición de reforma sería objeto de alguna relevante modificación en el trámite de Ponencia, como la inclusión, por acuerdo unánime de todos los ponentes, de la "incapacidad prolongada" entre los supuestos que podían determinar la delegación del voto o el voto telemáti$\mathrm{co}^{81}$. Tras ser objeto todavía de alguna importante precisión en Comisión ${ }^{82}$, el Pleno de la Cámara aprobaría la reforma reglamentaria sin más modificaciones ${ }^{83}$.

Así pues, el art. 85 del Reglamento tras esta reforma, distingue con claridad dos tipos de procedimientos para la delegación del voto según dicha delegación se produzca "por razón de paternidad o maternidad con ocasión de embarazo, nacimiento o adopción" o "en los supuestos de enfermedad o incapacidad prolongada" del diputado o diputada. Así, en el primer caso, el trámite es relativamente simple y se sustancia ante la Mesa de la Cámara (apartado 5) ${ }^{84}$. En cambio, en el segundo caso, en

79 Art. 23.1 de la Ley 1/1986, de 2 enero, Electoral de Andalucía, modificada por la Ley 5/2005, de 8 de abril.

${ }^{80}$ DSPA Plenos 41, de 25 de marzo de 2009.

${ }^{81}$ BOPA núm. 272, de 7 de julio de 2009.

${ }^{82}$ En efecto, relevante parece la posterior incorporación por la Comisión de Reglamento de una enmienda in voce apoyada por todos los grupos parlamentarios y que afectaba tanto a la exposición de motivos de la reforma como a su único artículo. Con ella se determinaba que los casos de "maternidad o paternidad" que habilitaban al diputado o diputada para delegar su voto o eventualmente emitirlo por procedimientos telemáticos quedaban circunscritos a aquellos que lo fueran "con ocasión de embarazo, nacimiento o adopción" (DSPA Comisiones núm. 220, de 8 de septiembre de 2009; BOPA núm. 294, de 9 de septiembre de 2009).

${ }^{83}$ DSPA Plenos núm. 58, de 7 de octubre de 2009. El texto definitivo de la reforma aparece publicado en el BOPA núm. 323, de 22 de octubre de 2009.

84 "La delegación de voto deberá realizarse mediante escrito dirigido por el diputado o diputada afectado a la Mesa del Parlamento, en el cual deberá constar el nombre del miembro de la Cámara que recibe la delegación, así como los debates y las votaciones donde habrá de ejercerse o, en su caso, el periodo de duración de aquella." 
el que previamente a su tramitación la Mesa habrá de establecer "los criterios generales para delimitar los supuestos que determinen dicha delegación", esta además "será acordada por el Pleno de la Cámara previo dictamen de la Comisión del Estatuto de los Diputados, que se pronunciará sobre las circunstancias que concurren en cada caso" (apartado 6). Finalmente, y como se ha apuntado ya, se contempla también de manera genérica y para todos los supuestos mencionados la habilitación para el diputado o diputada de "formas de voto por procedimientos telemáticos" (apartado 7).

Transcurridos varios años desde dicha reforma, cabe decir que la delegación del voto en las sesiones plenarias del Parlamento de Andalucía se ha convertida ya, como tantas otras, en una práctica rutinaria, resultando habitual al inicio de cada sesión la modificación del orden del día a instancias del Presidente de la Cámara para incluir el acuerdo, en su caso, por parte de esta, de las delegaciones de voto en supuestos de enfermedad o incapacidad prolongada del diputado o diputada. Por el contrario, el procedimiento de voto por procedimiento telemático -contemplado ciertamente como una posibilidad en el nuevo apartado 7 del art. 85- aún no ha sido objeto de desarrollo alguno ${ }^{85}$.

\section{PRIMERA REACGIÓN ANTE LOS SÍNTOMAS DE CRISIS DE LA DEMOGRACIA REPRESENTATIVA: EL FORTALEGI- MIENTO DE LA INICIATIVA LEGISLATIVA POPULAR}

El creciente distanciamiento de la ciudadanía en estos últimos años respecto de la clase política (achacable, sin ser exhaustivos, a un insatisfactorio funcionamiento de las instituciones y a la continua aparición de casos de corrupción en el ámbito público, todo ello en el contexto además de una prolongada crisis financiera y económica) parece haber alentado una cierta sensación de crisis en nuestro sistema de representación política de la que se han hecho eco diversos estudios y encuestas publicados en medios especializados y de comunicación. Probablemente, no fuera ajena a esa evidente sensación de desapego entre representantes y representados la aprobación por el Parlamento de Andalucía en el tramo final de la VIII Legislatura, mediante su tramitación directa y en lectura única ante el Pleno (art. 136 RPA), de una modificación de la Ley 5/1988, de 17 de octubre, de Iniciativa Legislativa Popular y de los Ayuntamientos ${ }^{86}$, y ello con la finalidad de facilitar la participación de la ciudadanía an-

${ }^{85}$ En la práctica, la delegación del voto se efectúa de la manera siguiente: concluida la votación mediante procedimiento electrónico, que es la modalidad de votación ordinaria que se utiliza siempre en el Pleno, el Presidente solicita del diputado que ostenta la delegación el sentido de su voto, comunicando después a los miembros de la Cámara el resultado final de la votación.

${ }^{86}$ Ley 8/2011, de 5 de diciembre. 
daluza en el procedimiento legislativo, reduciendo de 75.000 a 40.000 el número de firmas de ciudadanos necesarias para promover una iniciativa de esta naturaleza en el Parlamento. ${ }^{87}$ Ahora bien, la reforma no se detiene en este extremo, sino que también, como se establece en su nueva disposición final primera, las modificaciones realizadas en la Ley 5/1988 "que afecten a la composición y funcionamiento del Parlamento de Andalucía darán lugar a la adecuación normativa del Reglamento de la Cámara". En particular, según detalla el citado el precepto, "se determinará el procedimiento para articular la participación de las personas promotoras de las iniciativas legislativas populares en la presentación y defensa en el Pleno de la Cámara y en el seguimiento de los debates, en la forma que reglamentariamente se establezca, para que resulte equivalente a la de diputados y diputadas en las proposiciones de ley, así como su participación en la oportuna Comisión parlamentaria”.

Como puede observarse, la norma se refería exclusivamente a la necesidad de determinar el procedimiento de participación de las "personas" promotoras de las iniciativas legislativas populares en sede parlamentaria, excluyendo de manera implícita la participación de los ayuntamientos en dicha sede. Esta omisión sería no obstante corregida en la última de las reformas del Reglamento habida hasta ahora, como se verá más adelante ${ }^{88}$. En todo caso, el mandato del legislador autonómico tardaría más de diez meses en ser objeto de plasmación y desarrollo en el Reglamento del Parlamento, teniendo finalmente acogida el mismo a través de una modificación del art. 125 , encargado de regular de manera conjunta ambos tipos de iniciativas, si bien, como era lógico, la modificación del citado precepto reglamentario, consistente en crear un nuevo apartado, únicamente va a afectar en este momento a la tramitación parlamentaria de las iniciativas legislativas de origen ciudadano ${ }^{89}$. Así, se dispone en primer lugar que la presentación y defensa de la proposición en el debate de toma en consideración en Pleno "corresponderá a un representante de la comisión promotora designado por esta“. En segundo lugar, superada la toma en consideración y acordado su envío a la comisión competente, "dicho representante podrá estar presente en las comparecencias informativas de los agentes sociales y organizaciones interesadas en la regulación de que se trate, y asistir tanto a las reuniones de Comisión don-

${ }^{87}$ Art. 2 a). Otro tanto ocurre en el caso de la iniciativa popular de los ayuntamientos, quienes podrán también promover la misma por acuerdo, adoptado por mayoría absoluta, de los Plenos de veinticinco ayuntamientos de la Comunidad, o de diez cuando estos representen al menos globalmente a 40.000 electores (art. 2 b). Anteriormente debían ser también 75.000.

${ }^{88}$ Véase el apartado $\mathrm{V}$.

${ }^{89}$ BOPA núm. 90, de 24 de octubre de 2012. Dicha reforma fue también conocida en el ámbito político y en los medios de comunicación como "escaño 110", partiendo de los 109 escaños que componen el Parlamento de Andalucía. 
de se debata el dictamen de la proposición como al debate final en el Pleno, teniendo derecho a intervenir en tales sesiones, con voz, al comienzo del turno de los grupos parlamentarios y por el mismo tiempo que estos ${ }^{\text {“90. }}$.

De las siete iniciativas legislativas presentadas ante la Mesa del Parlamento de Andalucía, sólo una, mediante la que se pretendía una modificación de la Ley 1/1982, de 2 de enero, Electoral de Andalucía, para reforzar, entre otros aspectos, la proporcionalidad del sistema electoral, consiguió ser objeto del debate de toma en consideración por el Pleno en los nuevos términos previstos en el Reglamento. Su defensa la desempeñó desde la tribuna de oradores uno de los miembros de la Comisión promotora, que abrió y cerro el debate de la iniciativa, siendo esta finalmente rechazada por la Cámara ${ }^{91}$.

Debe destacarse también, por su carácter materialmente reglamentario, la aprobación en la IX Legislatura de dos nuevas resoluciones de la presidencia del Parlamento. La primera Resolución, de 14 de junio de 2012, tiene su origen en la Comisión de Investigación creada en relación con las ayudas sociolaborales a trabajadores afectados por expedientes de regulación de empleo y a empresas en crisis otorgadas por la Administración de la Junta de Andalucía durante el período 2001-2010 92 y regula diversos aspectos complementarios de la organización y funcionamiento de las comisiones de investigación que se contemplan en el Reglamento (arts. 51, 52 y 70.3), con una especial atención a las garantías de los comparecientes ante las mismas ${ }^{93}$. La segunda Resolución, de 2 de octubre de 2013, fue consecuencia de la prolongada vacante acaecida en la Dirección General de la Agencia Pública Empresarial de la Radio y Televisión de Andalucía tras la renuncia de su titular sin que se produjera una nueva elección por el Pleno, situación esta no contemplada en el Reglamento y que

90 Además del Parlamento de Andalucía, sólo el de Cataluña ha regulado en su Reglamento la participación de los promotores de una iniciativa legislativa popular en el procedimiento legislativo, si bien limitando su intervención al debate de totalidad y al debate final (arts. 105.2 y 112.1).

91 DSPA núm. 84, de 25 de junio de 2014; BOPA núm. 487, de 4 de julio de 2014. Respecto de las otras seis iniciativas legislativas ciudadanas, la primera de ellas decayó por no alcanzar el número necesario de firmas, una segunda no fue admitida a trámite y otras tres sí lo fueron pero su tramitación quedó suspendida tras la disolución de la Cámara por la Presidenta de la Junta de Andalucía el 26 de enero de 2015, circunstancia esta que también impidió conocer a la Mesa la última de las presentadas.

${ }^{92}$ La referida Comisión de Investigación fue creada por el Pleno a partir de sendas iniciativas del GPS y de IULV-CA con el mismo objeto. Otra presentada igualmente por el GPP-A en relación con dicho tema fue rechazada (DSPA 7, de 14 de junio de 2012; BOPA núm. 25, de 18 de junio de 2012).

${ }^{93}$ BOPA núm. 25, de 18 de junio de 2012. 
se solventó disponiendo la comparecencia ante la Comisión de Control de la citada Agencia del cargo o autoridad en el que se hubieran delegado las competencias y funciones de dicha Dirección General ${ }^{94}$.

\section{LA ÚLTIMA REFORMA (O MÁS, BIEN "REVISIÓN") DEL REGLAMENTO: LA TRASLAGIÓN AL ÁMBITO PARLA- MENTARIO DE LOS PRINCIPIOS DE "TRANSPARENCIA" Y "CALIDAD DEMOGRÁTICA"}

$\mathrm{Al}$ final de la IX Legislatura tuvo lugar, también mediante su tramitación directa y en lectura única ante el Pleno, la última de las reformas del Reglamento del Parlamento Andalucía, probablemente una de las de mayor calado en sus más de tres décadas de existencia, entre otras razones, por efectuar modificaciones de cierta trascendencia en varias de las materias propias del mismo ${ }^{95}$. Dicha reforma se funda de modo expreso, como indica su exposición de motivos, en el art. 10.3.19. ${ }^{\circ}$ del Estatuto de Autonomía, que contempla como uno de los objetivos básicos de la Comunidad Autónoma "la participación ciudadana en la elaboración, prestación y evaluación de las políticas públicas, así como la participación individual y asociada en los ámbitos cívico, social, cultural, económico y político, en aras de una democracia social avanzada y participativa". Además, buena parte de las novedades introducidas por esta reforma fueron consecuencia del Informe del Grupo de Trabajo sobre determinadas modificaciones legislativas y normativas en materia de transparencia y calidad democrática, constituido en el seno de la Comisión de Presidencia a finales de la anterior legislatura. ${ }^{96}$

En efecto, esta nueva reforma reglamentaria, que afecta a cerca de una veintena de artículos, se lleva a cabo a la luz de los citados principios de transparencia y calidad democrática, entendido el primero como facilidad en el acceso a cualquier información por parte de los ciudadanos, exceptuada aquella legal o reglamentariamente prevista, relativa a las actividades de la Cámara y sus miembros, mientras que el segundo hace referencia a la mejora de los procedimientos parlamentarios con el objetivo principal de involucrar en la mayor medida posible a los propios ciudadanos en la actividad política. Sobre estas bases, las modificaciones operadas en esta última reforma pueden clasificarse en tres tipos: $1^{\circ} .^{\circ}$ ) las que afectan al Estatuto de los Diputados;

94 BOPA núm. 306, de 4 de octubre de 2013.

${ }^{95}$ BOPA núm. 576, de 3 de diciembre de 2014.

96 BOPA núm. 720, de 18 de julio (votos particulares: BOPA núm. 721, de 20 de julio). Dicho informe fue aprobado por el Pleno en su sesión de 21 de julio de 2011 (BOPA núm. 725, de 27 de julio). 
$\left.2 .^{\circ}\right)$ las que conciernen a la organización y funcionamiento de la Cámara; y $3 .^{\circ}$ ) las relativas al procedimiento legislativo.

En primer lugar, respecto al régimen de los diputados, la reforma introduce una serie de innovaciones con las que, de manera nada velada, pues así se refleja en la exposición de motivos, se pretende alcanzar ese comportamiento "ejemplar" que los ciudadanos exigen cada vez con más rigor a sus representantes en un sistema democrático que se pretende "de calidad", y ello mediante una nueva regulación de la información tributaria que deben facilitar tanto los diputados como algunas personas de su entorno. Así, a dicha información se le dará publicidad con arreglo a las normas de transparencia que resulten de aplicación (art. 8.2), con la finalidad de poner a disposición de los ciudadanos la información más completa posible sobre las actividades y situación patrimonial de sus representantes, salvaguardando siempre el derecho a la intimidad de terceras personas (art. 16.4). Este principio de publicidad resulta también de aplicación a los grupos parlamentarios, de modo que la información sobre las subvenciones parlamentarias que reciban así como las cantidades que abonen a sus integrantes, además de ser como hasta ahora objeto de publicación en el BOPA, estará también disponible en el denominado Portal de Transparencia del Parlamento de Andalucía (art. 25.3 y 4 )

También se dota a la Mesa de la Cámara de la facultad de detraer las retribuciones, así como las indemnizaciones por gastos, de aquellos diputados que de modo injustificado dejen de asistir a las sesiones de los órganos parlamentarios de los que formen parte, siendo objeto de publicación al final de cada período de sesiones, en el citado Portal de Transparencia, tales asistencias (art. 13). Ciertamente el legislador reglamentario es consciente, y así lo hace constar expresamente en la exposición de motivos de la reforma, de que "la labor de los Diputados va más allá de la asistencia a los debates" "97. Pero también reconoce que la sociedad actual demanda que, además, cumplan con este deber de asistencia, interpretando esta demanda de presencia física por parte de los ciudadanos como interés en los asuntos que afectan a todos ${ }^{98}$. En el mismo sentido, se establece también que el desempeño por los diputados de actividades incompatibles sin contar con la preceptiva autorización podrá ser causa de privación de sus derechos, aunque siempre con las debidas garantías (art. 100.1 4. ${ }^{\circ}$ y 2).

97 De hecho, considera preciso "reconocer el esfuerzo invertido en actividades que «no se ven», como el recabar información sobre cuestiones de interés de los ciudadanos, la preparación de sus intervenciones, las actividades de negociación para alcanzar acuerdos y otras que suelen pasar desapercibidas".

98 El TC ha afirmado, desde temprana fecha, que la libertad ideológica no ampara un comportamiento de inasistencia generalizada a las sesiones parlamentarias, justamente por ese deber de asistencia que los reglamentos de las cámaras imponen a sus miembros (ATC 1227/1988, de 7 de diciembre). 
En segundo lugar, en lo que atañe a la organización y funcionamiento de la Cámara, desaparece la posibilidad, contemplada desde la I legislatura, de que puedan constituirse en grupo parlamentario los diputados de una formación política que hubiese obtenido un número de escaño no inferior a tres y, al menos, el cinco por ciento de los votos emitidos en el conjunto de Andalucía. En consecuencia, en la X legislatura sólo han podido constituirse grupos parlamentarios a partir de cinco diputados (art. 20.1), conforme establece como regla general el Reglamento desde sus orígenes. Se trata de una medida que ha suscitado no pocas críticas, sobre todo procedentes de aquellas formaciones políticas en principio minoritarias que pueden ver mucho más reducido su protagonismo en la Cámara legislativa en el caso de obtener una representación inferior al citado número ${ }^{99}$.

Mención especial merece, por otra parte, la ampliación temporal -producto de una fuerte y reiterada demanda social- del segundo período ordinario de sesiones, quedando el mes de julio comprendido también dentro del mismo. Además, se resuelve por fin la discrepancia existente respecto del régimen de convocatoria de sesiones extraordinarias de la Cámara entre el art. 103.3 del Estatuto de Autonomía y el art. 67 del Reglamento, incorporando como no podría ser de otra manera a este último las previsiones estatutarias con una redacción que mejora notablemente la mucho más farragosa del Estatuto ${ }^{100}$. También se refuerza el carácter público de las sesiones tanto del Pleno como de las Comisiones, al suprimirse la posibilidad antes existente de que aquel o estas pudieran declarar la sesión secreta por acuerdo de la

${ }^{99}$ En todo caso, esta modificación reglamentaria no ha tenido ninguna trascendencia en esta X Legislatura, pues las cinco formaciones políticas que se han constituido en otros tantos grupos parlamentarios han igualado o superado el número mínimo de escaños exigidos a tal efecto, a saber: PSOE-A (47), PP-A (33), Podemos (15), Ciudadanos-Partido de la Ciudadanía (9) e IULV-CA (5).

${ }^{100}$ Recordemos (nota 50) que el art 103.3 EAA atribuye la convocatoria de sesiones extraordinarias al Presidente de la Cámara, "previa aprobación por la Diputación Permanente, a petición de ésta, de una cuarta parte de los Diputados o del número de grupos parlamentarios que el Reglamento determine, así como a petición del Presidente de la Junta o del Consejo de Gobierno". Por su parte, en la redacción anterior del art. 67.3 RPA, que se remonta a la IV Legislatura (DSPA núm. 76, de 5 de mayo de 1995), se facultaba para dicha convocatoria a la Presidencia "a petición del Presidente o de la Presidenta de la Junta de Andalucía, de la Diputación Permanente o de la mayoría absoluta de los miembros de la Cámara", legitimación esta última contradictoria no sólo ya con el EAA actual sino también con el de 1981 (art. 27.4). El art. 67.3 RPA vigente en la actualidad dice lo siguiente: “(...) la Cámara sólo podrá celebrar sesiones extraordinarias a convocatoria de su Presidente o Presidenta, previa aprobación del orden del día por la Diputación Permanente, que se reunirá a iniciativa del Presidente o Presidenta o a petición de una cuarta parte de los Diputados o de dos Grupos parlamentarios. También se reunirá en sesión extraordinaria a petición del Presidente o Presidenta de la Junta o del Consejo de Gobierno. En dicha petición deberá figurar el orden del día que se propone para la sesión extraordinaria solicitada." 
mayoría absoluta de sus miembros (arts. 69 y 70). De otra parte, en el ámbito de la disciplina parlamentaria, se aborda la regulación de ciertos detalles del procedimiento para la imposición de sanciones a los Diputados, cuya aplicación en la mayoría de los asambleas legislativas, además de encontrarse prácticamente en desuso, deja mucho que desear desde la perspectiva del principio de tipicidad de las normas y del propio procedimiento sancionador, y ello a pesar de que hasta ahora el Tribunal Constitucional ha sabido adaptar tales garantías al ámbito parlamentario ${ }^{101}$. La nueva regulación pretende una aplicación más efectiva de las normas relativas a la disciplina parlamentaria, sin perjuicio de los principios reconocidos en el ordenamiento jurídico respecto del ámbito disciplinario, como el derecho de audiencia y a formular alegaciones, remitiendo a una resolución de la presidencia la regulación del concreto procedimiento $\left(\right.$ art. 100.2) ${ }^{102}$.

En tercer lugar, por lo que se refiere a aquellas innovaciones que tienen que ver con el procedimiento legislativo, se establece, como ya ocurriera en la IV Legislatura, una medida sin precedentes en nuestro derecho parlamentario, tanto estatal como autonómico, en esa búsqueda que claramente constituye el leit motiv de esta última reforma mediante la que se pretende encontrar un cierto equilibrio entre la participación ciudadana y la necesaria intervención de los agentes parlamentarios, especialmente la de los grupos que conforman la Cámara. En concreto, se trata de la posibilidad de que los ciudadanos, a través de las asociaciones que los representen, puedan plantear enmiendas a proyectos y proposiciones de ley, salvo en aquellos casos que versen sobre las materias excluidas de la iniciativa legislativa popular por la ya citada Ley 5/1988, de Iniciativa Legislativa Popular y de los Ayuntamientos ${ }^{103}$. En todo caso, algún grupo parlamentario deberá asumirlas para que puedan proseguir su tramitación (art. 114 bis).

${ }^{101}$ STC 129/2006, de 24 de abril.

102 Dicha resolución se encuentra, en el momento en el que se escriben estas páginas, pendiente de aprobación. De otra parte, debe hacerse constar la modificación de las funciones de la Comisión de Gobierno Interior y Peticiones, que pasa a llamarse Comisión Consultiva de Nombramientos, Relaciones con el Defensor del Pueblo Andaluz y Peticiones (art. 49). Sus anteriores competencias relativas al presupuesto del Parlamento pasan a la Mesa de la Cámara (artículo 28.1.2. ${ }^{\circ}$ ), en consonancia con la regulación de otros Parlamentos y del Congreso de los Diputados. Así pues, dicha Comisión queda ahora configurada como un verdadero órgano de asesoramiento en relación con los nombramientos que deba efectuar el Parlamento, regulándose a tal efecto con un alto nivel de detalle el procedimiento para declarar, en su caso, la idoneidad de las personas propuestas $\left(49.2 .4^{\circ}{ }^{\circ}\right.$ ).

103 Son las siguientes (art. 3): 1) Aquellas que no sean de la competencia legislativa de la Comunidad Autónoma. 2) Las de naturaleza tributaria. 3) La planificación económica de la Comunidad Autónoma. 4) Las mencionadas en los artículos 187 y 190 del Estatuto de Autonomía. 5) Las relativas a la organización de las instituciones de autogobierno. 
Finalmente, además de incluir a los ayuntamientos en igualdad de condiciones con los ciudadanos respecto de la tramitación parlamentaria de las iniciativas legislativas reguladas en la Ley 5/1988 (subsanándose así su olvido en la anterior refor$\mathrm{ma}^{104}$ ), al objeto de evitar dilaciones en dicha tramitación se establece que aquellas deberán ser incluidas en el orden del día de una sesión plenaria en el plazo máximo de dos meses desde la fecha de verificación por la Mesa de los requisitos legales y reglamentarios establecidos para su admisión a trámite (art. 125.2). Por último, se mantiene el carácter anual del debate sobre el estado de la Comunidad, si bien se suprime el requisito de que dicho debate deba celebrarse durante el segundo período de sesiones. Se dota así de mayor flexibilidad al mismo para que su celebración pueda ajustarse mejor a las circunstancias del momento (art. 147.1).

Como conclusión, resulta fácil constatar que la transparencia se constituye en el principio básico y transversal que inspiran esta última reforma. De hecho, su plasmación más cabal es el ya citado Portal de Transparencia del Parlamento de Andalucía, ubicado en su página web ${ }^{105}$. Este Portal de Transparencia se configura, según la propia exposición de motivos de la reforma, como "cauce instrumental" para garantizar la efectividad de todas estas medidas y proporcionar "una imagen veraz y completa, dinámica y actualizada de la organización del Parlamento y de su actividad". Así, en dicho Portal estará disponible toda la información que venga impuesta por la Ley 19/2013, de 9 de diciembre, de transparencia, acceso a la información pública y buen gobierno, por la Ley 1/2014, de 24 de junio, de Transparencia Pública de Andalucía, y también por el propio Reglamento, correspondiendo a la Mesa aprobar las normas y adoptar las medidas que resulten precisas para garantizar la transparencia de la actividad de la Cámara y el derecho de acceso a la información pública del Parlamento de Andalucía (art. 66 bis) ${ }^{106}$.

${ }^{104}$ Art. 125.3 RPA.

$105 \mathrm{http} / / / \mathrm{www}$.parlamentodeandalucia.es/opencms/export/transparencia/iniciotransparencia.htm. Tienen también en sus páginas web algún tipo de enlace o portal relacionado con la "transparencia" los parlamentos de Aragón, Asturias, Baleares, Cantabria, Castilla-La Mancha, Navarra y La Rioja. Además, los parlamentos de Canarias (arts. 213 a 215), Comunidad Valenciana (art. 110 ter), Extremadura (arts. 21.2, 32.3, 119.7 y 120) y País Vasco (arts. 108 y 109) hacen expresa referencia en sus respectivos reglamentos a los mismos.

106 Véase a este respecto el Acuerdo de la Mesa del Parlamento de Andalucía, de 25 de junio de 2014, sobre Normas relativas al derecho de acceso a la información en el Parlamento de Andalucía (BOPA núm. 485, de 2 de julio de 2014. 


\section{PARA CONGLUIR: ALGUNAS REFORMAS NEGESARIAS Y OTRAS SIEMPRE PENDIENTES}

Evidentemente, las reformas más ineludibles que sigue precisando el Reglamento del Parlamento de Andalucía tienen un carácter eminentemente técnico y vienen exigidas por la necesaria adaptación -transcurridos ya más de ocho años desde la entra en vigor del Estatuto de Autonomía- de buena parte de su regulación a las nuevas prescripciones de nuestra norma institucional básica. Tan es así que se dan todavía casos de abierta contradicción entre ambas normas, si bien es cierto que se resuelven en la práctica por la aplicación directa de las disposiciones estatutarias en virtud del principio de jerarquía normativa ${ }^{107}$.

Pero, además, existen algunos otros aspectos del Reglamento que precisan también de una tan conveniente como siempre postergada reforma ${ }^{108}$. Tal vez porque, desde la perspectiva de los agentes políticos que operan no solo ya en el Parlamento andaluz sino en todas las cámaras legislativas en general, su necesidad -a veces, incluso su urgencia- no es percibida de igual forma que por quienes tienen la función de asesorar y auxiliar técnicamente en el adecuado cumplimiento de los procedimientos parlamentarios. Y ello sobre la convicción de que un reglamento bien resuelto técnicamente, aparte de dotar a la actividad parlamentaria de una cierta previsibilidad y seguridad jurídica, contribuye a hacer más eficaz el trabajo de las cámaras y sus miembros, mejorando en definitiva la calidad del mismo.

107 Así ocurre, por ejemplo, con el procedimiento de investidura del Presidente de la Junta, en el supuesto de que ningún candidato obtuviera la confianza de la Cámara dos meses después de la primera votación (arts. 118.3 EAA y 138.7 RPA); o con la mayoría necesaria para entender aprobada la propuesta de reforma del EAA [arts. 248.1 b) EAA y 128.1 RPA].

108 Sin poder ser exhaustivos, habría que destacar aquellas reformas con incidencia en temas socialmente tan relevantes como los derechos de los ciudadanos ante los órganos de la Cámara [mejor regulación del derecho de petición contemplado en el art. 49.2.4. ${ }^{\circ} \mathrm{RPA}$ y reconocido ahora también en el art. 30.1 d) EAA], o tan esenciales para formar y expresar la voluntad del Parlamento como son el trámite de calificación de enmiendas en el procedimiento legislativo (sobre todo tras la nueva doctrina constitucional iniciada con las SSTC 119/2011 y 136/2011) o el procedimiento de votación (art. 86 RPA; al respecto la STC 361/2006). Todo ello sin olvidar alguna otra reforma cuya pertinencia sería consecuencia necesaria de la propia jurisprudencia del TC (en concreto, de la STC 223/1996), sobre atribución exclusiva al Consejo de Gobierno del juicio sobre la incidencia presupuestaria de las enmiendas a los proyectos de ley, así como también de las proposiciones de ley y sus enmiendas (arts. 190.1 EAA y 115.5 y 124.4 y 6 RPA). 


\section{BIBLIOGRAFÍA}

- CARMONA CONTRERAS, A. M.: "La elaboración de las normas", en M.J. Terol Becerra (dir): Comentarios al Estatuto de Autonomía para Andalucía, Tirant lo Blanch, Valencia, 2009 (págs. 343-353).

- MORALES ARROYO, J. M.: Comentario al art. 102, en P. Cruz Villalón-M. Medina Guerrero (dirs.): Comentario al Estatuto de Autonomía para Andalucía, (vol. III), Parlamento de Andalucía, Ideas Más Tecnología, Sevilla, 2012 (págs. 1668-1683).

- MORALES ARROYO, J. M. y TEROL BECERRA, M. J. (eds.) : Presentación del Reglamento del Parlamento de Andalucía. Textos Legislativos 3, Servicio de Publicaciones del Parlamento de Andalucía, Sevilla, 1997 (págs. 15-27).

- PORRAS NADALES, A. J. "La forma de gobierno en Andalucía", en Muñoz Machado. S.-Rebollo Puig. M.: (dirs.): Comentarios al Estatuto de Autonomía para Andalucía, Thomson Civitas, Madrid, 2008 (págs. 869-904).

- SANTAOLALla LÓPEZ, F.: Derecho Parlamentario Español, Madrid, Dykinson, 2013.

- SEVILLA MERINO, J.: "El voto no presencial de sus señorías". La Ley, núm. 7110 , de 9 de febrero de 2009 ( págs. 1-6).

- TERRÓN MONTERO, J: "La ausencia temporal del diputado por motivos relevantes: posibles soluciones", en J. Cano Bueso (coord.): El Parlamento de Andalucía. Órganos de extracción parlamentaria. Órganos consultivos o de participación de designación parlamentaria. Jornadas de Estudio Organizadas por el Parlamento de Andalucía. XX Aniversario del Estatuto. Parlamento de Andalucía, Comares, Granada, 2004 (págs. 177-199).

- TUDELA ARANDA, J.: "La reforma del Reglamento de las Cortes de Aragón en el contexto del Parlamentarismo Autonómico". Revista Aragonesa de Administración Pública núm. 12, 1998 (págs. 23-59). 